\title{
Targeting chemoresistant colorectal cancer via systemic administration of a BMP7 variant
}

\author{
Veronica Veschi ${ }^{1}$ - Laura R. Mangiapane ${ }^{1}$ - Annalisa Nicotra ${ }^{1} \cdot$ Simone Di Franco ${ }^{1}$ - Emanuela Scavo ${ }^{1}$. \\ Tiziana Apuzzo $^{1}$ - Davide S. Sardina ${ }^{1} \cdot$ Micol Fiori $^{2} \cdot$ Antonina Benfante $^{1} \cdot$ Maria L. Colorito ${ }^{1} \cdot$ Gianfranco Cocorullo $^{1}$. \\ Felice Giuliante $^{3,4} \cdot$ Calogero Cipolla $^{1}$ - Giuseppe Pistone ${ }^{5} \cdot$ Maria Rita Bongiorno $^{5}$. Aroldo Rizzo $^{6}$. \\ Courtney M. Tate ${ }^{7} \cdot{\text { Xiaohua } \mathrm{Wu}^{7} \cdot \text { Scott Rowlinson }}^{7} \cdot$ Louis F. Stancato $^{7} \cdot$ Matilde Todaro $\mathbb{D}^{5} \cdot$ Ruggero De Maria $^{3,4}$. \\ Giorgio Stassi ${ }^{1}$
}

Received: 10 April 2019 / Revised: 23 September 2019 / Accepted: 25 September 2019 / Published online: 7 October 2019

(c) The Author(s) 2019. This article is published with open access

\begin{abstract}
Despite intense research and clinical efforts, patients affected by advanced colorectal cancer (CRC) have still a poor prognosis. The discovery of colorectal (CR) cancer stem cell (CSC) as the cell compartment responsible for tumor initiation and propagation may provide new opportunities for the development of new therapeutic strategies. Given the reduced sensitivity of CR-CSCs to chemotherapy and the ability of bone morphogenetic proteins (BMP) to promote colonic stem cell differentiation, we aimed to investigate whether an enhanced variant of BMP7 (BMP7v) could sensitize to chemotherapyresistant CRC cells and tumors. Thirty-five primary human cultures enriched in CR-CSCs, including four from chemoresistant metastatic lesions, were used for in vitro studies and to generate CR-CSC-based mouse avatars to evaluate tumor growth and progression upon treatment with BMP7v alone or in combination with standard therapy or PI3K inhibitors. BMP7v treatment promotes CR-CSC differentiation and recapitulates the cell differentiation-related gene expression profile by suppressing Wnt pathway activity and reducing mesenchymal traits and survival of CR-CSCs. Moreover, in CR-CSC-based mouse avatars, BMP7v exerts an antiangiogenic effect and sensitizes tumor cells to standard chemotherapy regardless of the mutational, MSI, and CMS profiles. Of note, tumor harboring PIK3CA mutations were affected to a lower extent by the combination of BMP7 $v$ and chemotherapy. However, the addition of a PI3K inhibitor to the BMP7v-based combination potentiates PIK3CA-mutant tumor drug response and reduces the metastatic lesion size. These data suggest that BMP7v treatment may represent a useful antiangiogenic and prodifferentiation agent, which renders CSCs sensitive to both standard and targeted therapies.
\end{abstract}

These authors contributed equally: Ruggero De Maria, Giorgio Stassi

Supplementary information The online version of this article (https:// doi.org/10.1038/s41388-019-1047-4) contains supplementary material, which is available to authorized users.

Ruggero De Maria

ruggero.demaria@unicatt.it

$\triangle$ Giorgio Stassi

giorgio.stassi@unipa.it

1 Department of Surgical, Oncological and Stomatological Sciences (DICHIRONS), University of Palermo, 90127 Palermo, Italy

2 Department of Oncology and Molecular Medicine, Istituto Superiore di Sanità, Rome, Italy

3 Istituto di Patologia Generale, Università Cattolica del Sacro

\section{Introduction}

Advanced colorectal cancer (CRC) is still a major challenge for clinical oncologists, being among the top causes of cancer-related death worldwide [1]. Cancer stem cells

Cuore, 00168 Rome, Italy

4 Fondazione Policlinico Universitario A. Gemelli-I.R.C.C.S., 00168 Rome, Italy

5 Department of Health Promotion Sciences, Internal Medicine and Medical Specialties (PROMISE), University of Palermo, 90127 Palermo, Italy

6 Pathology Unit, Ospedali Riuniti Villa Sofia-Cervello, Palermo, Italy

7 Lilly Research Laboratories, Lilly Corporate Center, Indianapolis, IN 46285, USA 
(CSCs) are key players in tumor initiation and development of metastasis [2, 3]. In recent years, many studies investigating the biological behavior of CSCs inspired the design of innovative therapeutic strategies for CRC. Genetic and epigenetic changes, overexpression of antiapoptotic proteins, and enhanced DNA repair machinery define the common traits of CSCs $[4,5]$. The acquisition of an epithelial-mesenchymal transition (EMT) phenotype confers to CSCs the ability to invade and metastasize [6]. Among the most studied CSC markers, CD133 has been reported to identify CR-CSCs [7]. More recently, we determined that a splicing variant of CD44, CD44v6, is a functional marker expressed in CR-CSCs able to migrate and engraft at distant sites [8]. In line with the enhanced Wnt signaling observed in CR CD44v6 ${ }^{+}$cells, $\beta$-catenin activation induces CD44v6 expression in CR-CSCs. This pathway is sustained by the activation of the PI3K/AKT pathway, which promotes $\beta$-catenin activation through the inhibition of GSK3 $\beta$, a key component of its destruction complex [8]. According to the multistep model, the progressive acquisition of mutations in proto-oncogenes or tumor suppressor genes defines specific stages of CRC [9]. Aberrant alterations of principal components of pathways involved in intestinal stem cell self-renewal endorse the disruption of intestinal niche equilibrium [10]. In addition to Wnt, Notch, and Sonic hedgehog pathways, bone morphogenetic proteins (BMPs) finely regulate the intestinal niche homeostasis balancing self-renewal and differentiation $[11,12]$. BMPs are members of the TGF- $\beta$ superfamily and regulate many fundamental biological processes during development. BMPs bind both type I and type II receptors (BMPR1A, BMPR1B, and BMPR2) to achieve a variety of cellular functions [13]. The activation of this pathway promotes the phosphorylation of SMAD1, 5 , and 8 that in association with SMAD4 regulates the expression of genes involved in the differentiation process [14, 15]. BMP antagonists (gremlin and noggin) tightly modulate BMPs activity [16]. In healthy colon mucosa, the expression of BMPs and their antagonists is polarized. BMPs are mainly located at the top, while BMP antagonists at the base of colon crypt [17]. Alterations of BMP pathways can imbalance the homeostasis of the intestinal stem cell niche, thus favoring the development and progression of CRC. Indeed, the loss of BMPR2 and SMAD4 expression has been reported in sporadic CRC, whereas germline mutations of BMPRI and SMAD4 genes have been demonstrated to enhance the susceptibility to develop juvenile polyposis, supporting that TGF- $\beta$ signaling inactivation plays a key role in CRC development [18-22]. In intestinal stem cells, BMP signaling counteracts the Wnt pathway activity by impairing the nuclear accumulation of $\beta$-catenin through a PTEN-dependent AKT inhibition [23]. This antagonistic activity of BMP signaling against stem cells and Wnt pathway seems preserved in the cancer counterpart as indicated by the ability of BMP4 to promote differentiation and apoptosis of CR-CSCs [24].

BMP expression varies across tumor subtypes [25]. BMP7 is widely expressed in many tumors including breast, prostate, and colon cancer, and it is implicated in the regulation of cell proliferation [26-28]. However, its functional association with tumorigenicity and metastasis formation is still poorly understood. Recently, a human variant of BMP7 with enhanced stability and solubility (BMP7v) has been developed, by introducing mutations into the $\mathrm{N}$ terminus of BMP7 prodomain [29]. In glioblastoma stem-like cells, BMP7v impairs their proliferation and invasive capability by inducing differentiation [30] and significantly decreases angiogenesis. BMP7v, unlike BMP7, is not recognized by most of the BMP endogenous antagonists, such as noggin, gremlin, chordin, and chordin-like 2, due to reduced binding [31]. Disease progression in CRC is mostly due to the emergence of chemoresistant CSCs after therapeutic interventions [32]. Different mechanisms and biomarkers have been proposed so far to study and predict chemoresistance. Both microsatellite instability (MSI) and consensus molecular subtype (CMS) profiles correlate with the chemotherapy response in CRC. Specifically, MSI CRCs have been correlated with a better prognosis [33] but also with a lack of benefit from oxaliplatin (oxa) plus 5-fluorouracil (5-FU) therapy [34, 35]. CMS2 CRC is as the subset that most benefits from the chemotherapy, while the CMS4 results resistant to conventional therapy [36, 37]. We demonstrated that the activation of the PI3K/AKT pathway is essential for preserving the stem cell status in CRC CD44v6 ${ }^{+}$cells [8]. PI3K activation results in the onset of alternative signaling pathways, including Wnt- $\beta$-catenin axis activation that promotes CR-CSC survival, invasion, and development of metastases [38]. Using the BMP7v, here we have studied the possibility of targeting chemoresistant CRC through the induction of CSC differentiation. We provide evidence supporting the use of BMP7v in combination with chemotherapeutic compounds and/or PI3K inhibitors for CRC treatment.

\section{Results}

\section{BMP7 is highly expressed in low-grade CRC patients}

In accordance with the current literature, we found BMP7 abundantly expressed in CRC tissues, compared with peritumoral mucosa (Fig. 1a). BMP7 expression was limited to the apical part and absent in the $\mathrm{LGR}^{+}$stem 


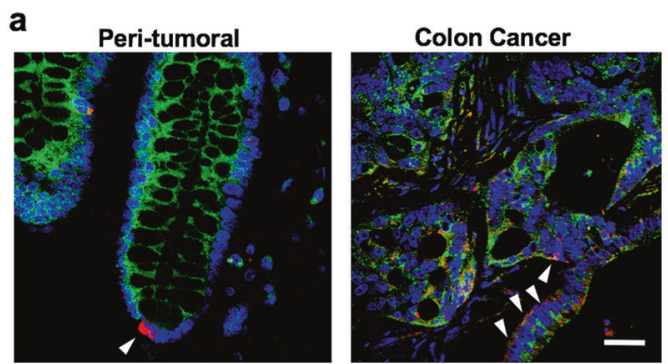

Toto-3 BMP7 LGR5

d

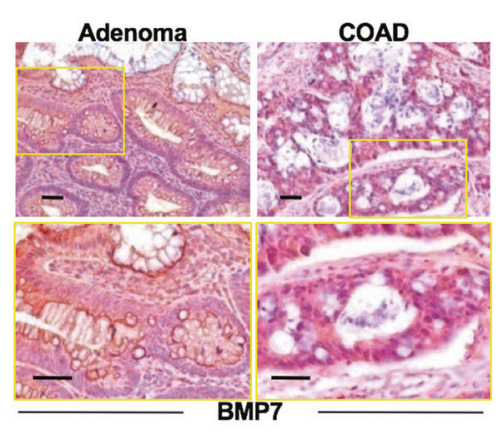

g

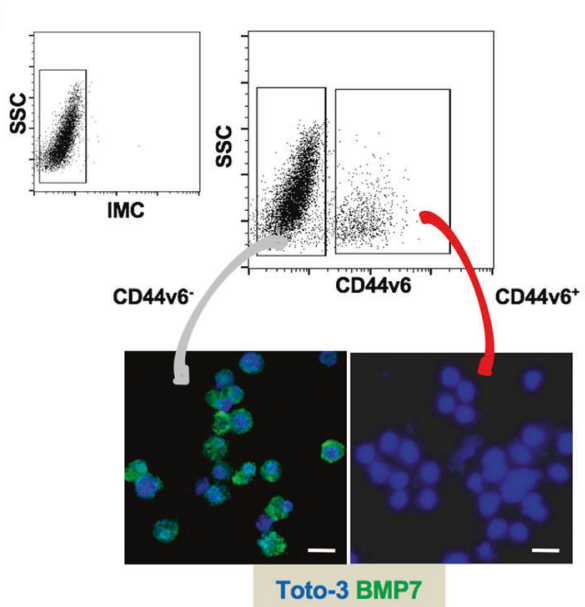

b

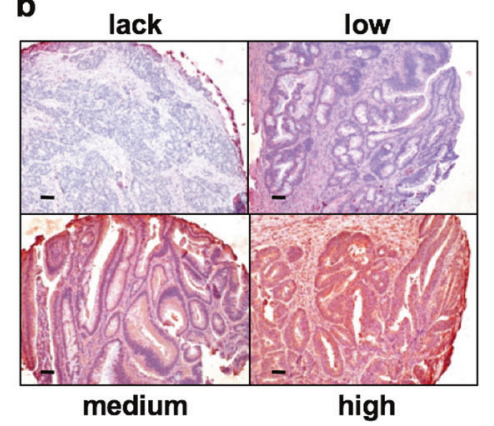

C

\begin{tabular}{|c|c|c|}
\hline Grade & Pts & $\begin{array}{c}\text { BMP7 Score } \\
\text { medium/high(\%) }\end{array}$ \\
\hline I-II & 131 & $100(76 \%)$ \\
\hline III & 27 & $8(30 \%)$ \\
\hline \multicolumn{2}{|c|}{ Pearson's Chi Square test: $p=6.06 E-06$} \\
\hline
\end{tabular}

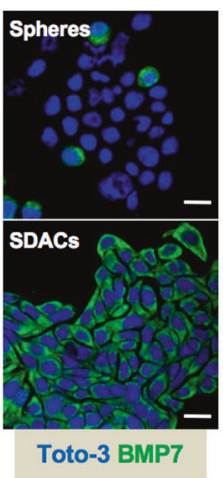

$\mathbf{f}$
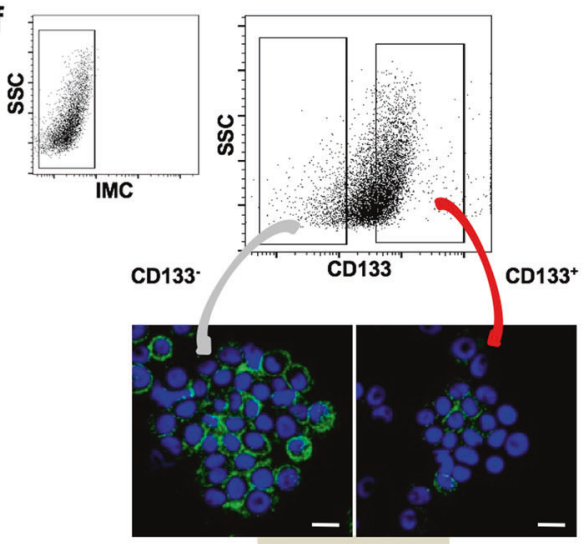

Toto-3 BMP7

h

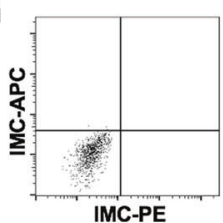

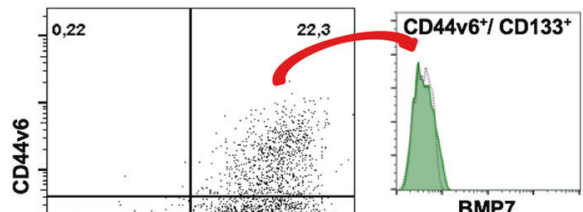
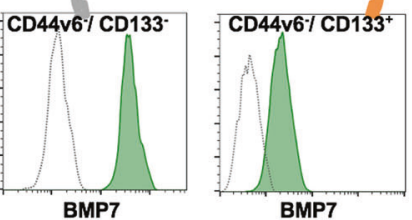

cells located at the very base of the cancer gland (Fig. 1a, left panel). Analysis of a cohort of $158 \mathrm{CRC}$ patients showed a significant correlation between medium/high BMP7 expression and the low-grade (I-II) tumors, which was confirmed by the analysis of a cohort of CRC in R2 database (Fig. 1b, c and Supplementary Fig. 1a). Interestingly, BMP7 was found highly expressed in both colon adenoma and adenocarcinoma, suggesting this phenomenon as an early event in cancer (Fig. 1d). In line with the expression of BMP7 in the differentiated part of the colon gland, BMP7 was remarkably expressed in sphere-derived adherent cells (SDACs), while it was present in few cells across CRC spheres, which are enriched in stem-like cells (Fig. 1e). Moreover, we found that CD133- cells showed a higher percentage of BMP7-expressing cells as compared with the $\mathrm{CD}_{133^{+}}$compartment (Fig. 1f and Supplementary Fig. 1b, c). Interestingly, CD44v6 ${ }^{+}$cells lacked BMP7 expression, which was conversely confined to the CD44v6- cell compartment (Fig. 1g and Supplementary Fig. 1d, e). In accordance with the immunofluorescence studies, flow cytometry analysis showed that BMP7 is expressed in $\mathrm{CD}_{133^{-}} / \mathrm{CD}_{4} 4 \mathrm{v}^{-}$cells and in a fraction of 
Fig. 1 BMP7 is confined to differentiated CRC cells. a Immunofluorescence analysis of BMP7 (green color) and LGR5 (red color) on peritumoral mucosa and colon cancer paraffin-embedded tissues performed on CSC\#8. One representative tumor from twenty different tumors examined is shown. Nuclei were counterstained by Toto-3 (blue color). White arrowheads indicate $\mathrm{LGR}^{+}$cells at the base of colon crypt. The scale bar represents $100 \mu \mathrm{m}$. b Immunohistochemical analysis of BMP7 on CRC TMAs in lack, low, medium, and high staining intensity (red color). Nuclei were counterstained by aqueous hematoxylin (blue color). The scale bar represents $100 \mu \mathrm{m}$. c Association of BMP7 expression with score medium/high and the pathological grading in CRC TMAs provided by TRISTAR technology group. d Immunohistochemical analysis of BMP7 (red color) in paraffin-embedded sections of colon adenomas and adenocarcinoma (COAD). Nuclei were counterstained by aqueous hematoxylin (blue color). The scale bar represents $100 \mu \mathrm{m}$. e Immunofluorescence analysis of BMP7 (green color) in CRC sphere cells and their differentiated progeny SDACs. One representative of fifteen different CRCSC lines (CSC\#1-3, 5-7, 10,11, 14-16, 18, 25, 33, and 40) is shown. Nuclei were counterstained by Toto-3 (blue color). The scale bars represent $20 \mu \mathrm{m}$. f Representative flow cytometry analysis of CD133 in CRC sphere cells and its relative isotype-matched control (IMC) (upper panels) performed on $\mathrm{CSC} 44,8$, and 23-26. Immunofluorescence analysis of BMP7 (green color) in CD133 ${ }^{+}$and CD133 enriched CRC sphere cell subpopulations (lower panels). Nuclei were counterstained by Toto-3 (blue color). The scale bars represent $20 \mu \mathrm{m}$. g CD44v6 expression profiles of cells as described in $\mathbf{f}$ (upper panels). Expression of BMP7 (green color) in CD44v6 $6^{+}$and CD44v6 $6^{-}$enriched CRC sphere cell subpopulations assessed by immunofluorescence analysis (lower panels). Nuclei were counterstained by Toto-3 (blue color). The scale bars represent $20 \mu \mathrm{m}$. h Flow cytometry analysis of BMP7 (green histograms) in enriched CD44v6 $6^{-} / \mathrm{CD} 133^{-}$, $\mathrm{CD} 44 \mathrm{v} 6^{-} / \mathrm{CD} 133^{+}$, and $\mathrm{CD} 44 \mathrm{v} 6^{+} / \mathrm{CD} 133^{+} \mathrm{CRC}$ subpopulations performed as shown in $\mathbf{f}$. Dotted line histograms indicate the relative IMC

$\mathrm{CD}_{133^{+}}$cell compartment, whereas it is nearly undetectable in enriched CD44v6 $6^{+} / \mathrm{CD} 133^{+}$stem-like cells (Fig. 1h). These data demonstrate that BMP7 is predominantly expressed in differentiated CRC cell population, particularly in low-grade CRCs.

\section{BMP7v affects CD44v6 expression in CR-CSCs}

In order to define the potential of BMP7 as a prodifferentiation agent, we next evaluated whether the BMP signaling pathway components were conserved in a CRC model. We observed that type I and type II BMP receptors are expressed in both $\mathrm{CD} 44 \mathrm{v} 6^{+}$and $\mathrm{CD} 44 \mathrm{v} 6^{-}$fraction with more pronounced expression levels of BMPR2 in the CD44v6 ${ }^{-}$counterpart (Supplementary Fig. 2a, b). In order to investigate the effects of BMP7 on CR-CSCs, we used a modified BMP7 with enhanced stability and solubility $(\mathrm{BMP} 7 \mathrm{v})$ as previously described [30]. The dose concentration of $100 \mathrm{ng} / \mathrm{ml}$ of $\mathrm{BMP} 7 \mathrm{v}$ corresponded to the IC50 and was also preferred for the in vitro ability to inhibit the colony forming capacity of CR-CSCs even in the presence of high doses of BMP antagonists, gremlin, and noggin (Supplementary Fig. 2c, d). CD44v6 ${ }^{+}$cells exposed to BMP7v up to 21 days displayed a gradual morphological differentiation (Fig. 2a), paralleled by the acquisition of CK20 expression (Fig. 2b). In accordance, BMP7v significantly reduced the percentage of cells expressing the CD133/CD44v6 CSC markers and increased the number of $\mathrm{CDX}^{+}$cells within CRC spheres (Fig. 2c, $\mathrm{d}$ and Supplementary Fig. 2e, f). In a cohort of CRC patients, expression levels of CDX2 are inversely correlated with tumor grading (Supplementary Fig. 2g).

Interestingly, flow cytometry analysis of primary CRC sphere cells transduced with a $\beta$-catenin/TOP-dGFP reporter lentiviral vector showed that exposure to BMP7v was able to progressively decrease $\beta$-catenin activity and CD44v6 expression (Fig. 2e and Supplementary Fig. 2h). Moreover, BMP7v treatment caused the reduction of $\beta$-catenin activity and differentiation of CRC organoid, which was highlighted by lumen formation and cell polarization (Fig. $2 \mathrm{f}$ and Supplementary Fig. 2i). In the presence of BMP7 $\mathrm{v}, \mathrm{CD} 44 \mathrm{v} 6^{+} \mathrm{CRC}$ sphere cells acquired E-cadherin expression, displayed loss of vimentin and reduction of nuclear $\beta$-catenin (Fig. 2g). A large cohort of CRC patients showed a positive correlation between the expression levels of BMP7 and E-cadherin $(\mathrm{CDHI})$ (Supplementary Fig. 3a). In agreement, xenograft tumors generated by the injection of CR-CSCs (CSC\# 1, 8, and 25), displayed a major number of cells expressing E-cadherin after BMP7v treatment (Supplementary Fig. 3b). Accordingly, the in vitro invasive capacity of CD44v6 ${ }^{+}$CR-CSCs was significantly impaired following treatment with BMP7v (Fig. 2h). Following $96 \mathrm{~h}$ of treatment, CD44v6 ${ }^{+}$fraction exhibited a more pronounced sensitivity to BMP7 $\mathrm{v}$-induced cell death than CD44v6 $6^{-}$cells (Fig. 2i). Although BMP7v treatment did not significantly affect G0/G1 to G2/M phase transition, it enhanced to a small extent the sub-G0 phase in CD44v6 ${ }^{+}$CR-CSCs (Fig. $2 \mathrm{j}$ and Supplementary Fig. 3c). In line with the induction of cell death, BMP7v treatment induced activation of both PARP and Caspase- 3 and a downregulation of Bcl-2 and Bcl-xL in CD44v6 ${ }^{+}$cells (Fig. 2k and Supplementary Fig. 3d, e). These data indicate that BMP7v selectively targets the CD44v6 ${ }^{+}$CSC compartment by counteracting its Wnt pathway activity and antiapoptotic machinery.

\section{BMP7v hampers the self-renewal capacity of CR- CSCs}

We have already reported that BMP7v activity is resistant to the majority of BMP antagonists, such as noggin and chordin [31]. Given that only some cancers express high levels of gremlin and noggin [39, 40] we sought to investigate their inhibitory effects on both BMP4 and BMP7v. Although BMP4 was not able to accomplish its function in the presence of gremlin and noggin, BMP7v 
a

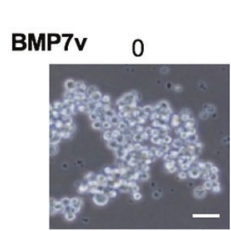

d
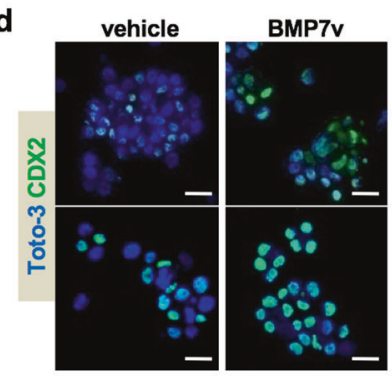

$\mathbf{f}$

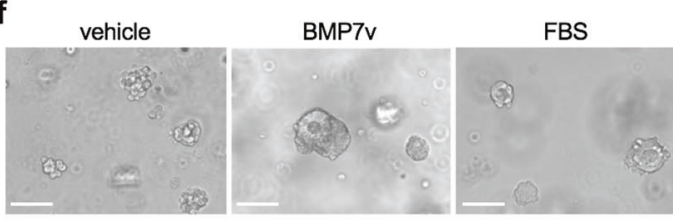

g

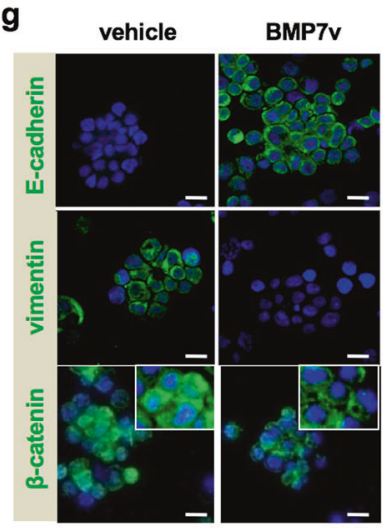

i

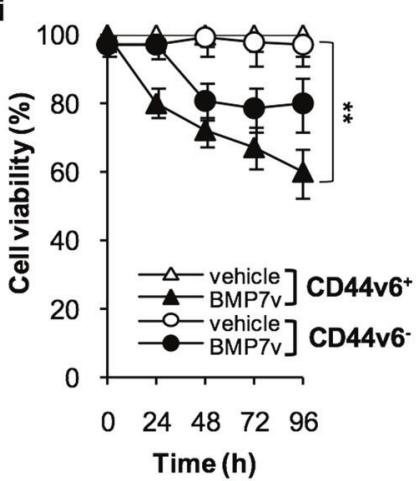

b

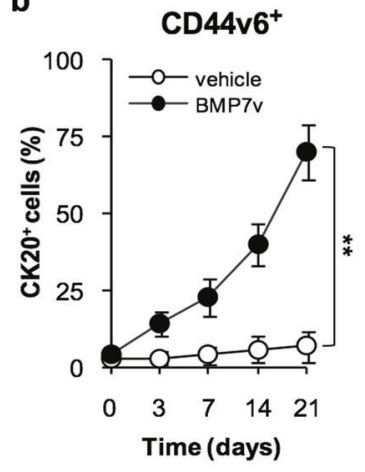

C

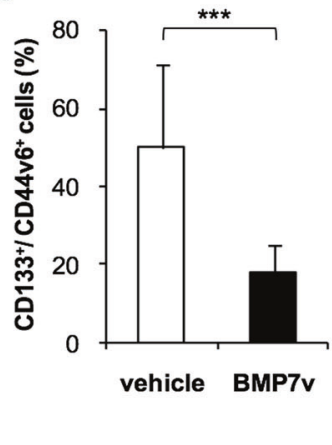

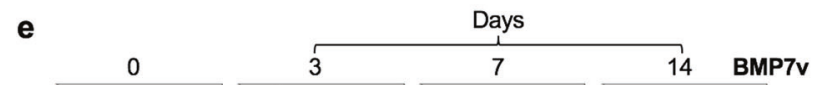
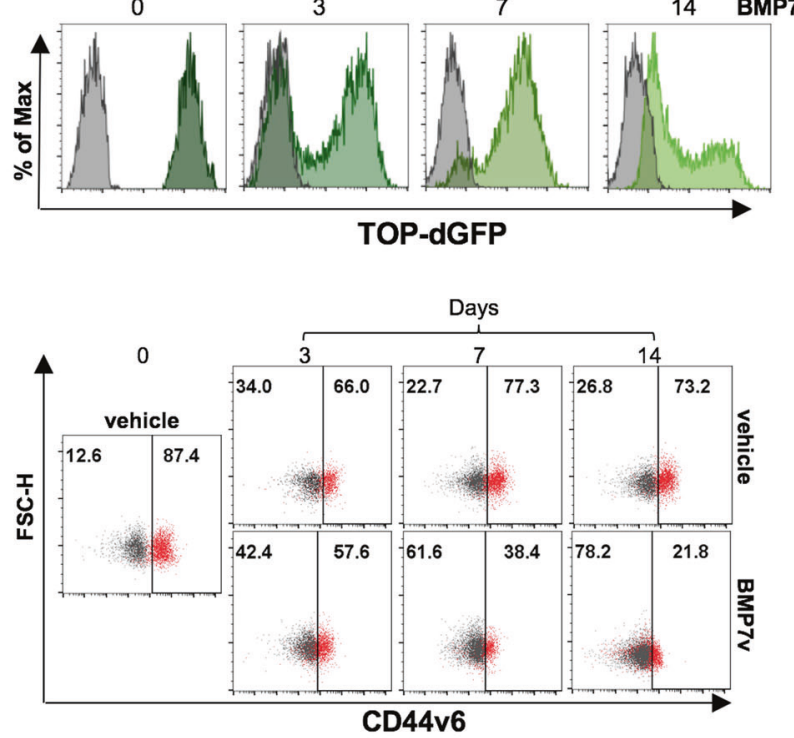

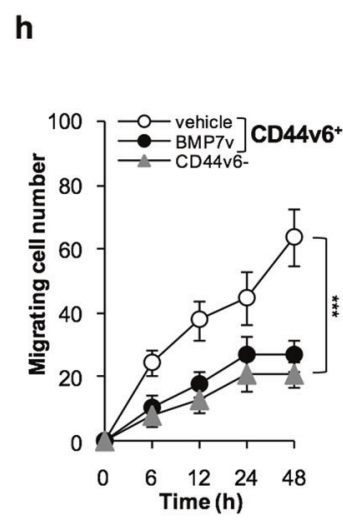

h

j

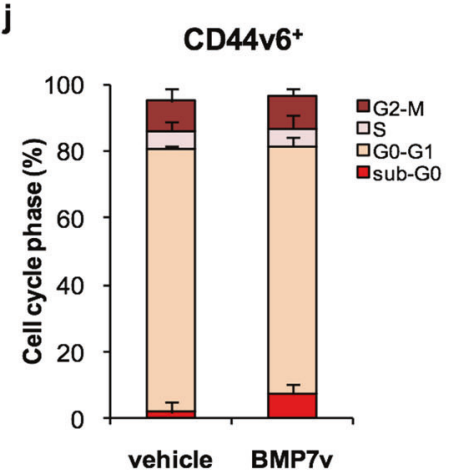

k

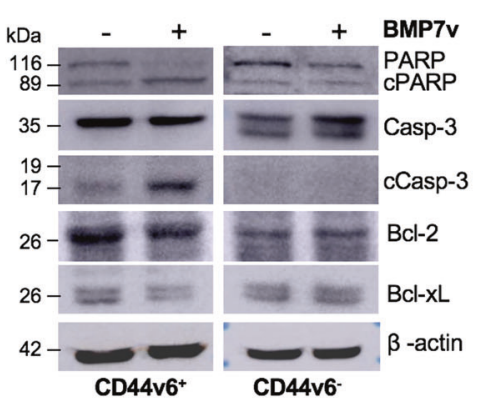

reduced the colony forming capacity of CR-CSCs more efficiently than BMP4, even in the presence of BMP inhibitors (Fig. 3a). We have previously demonstrated that
CD44v6 ${ }^{+}$cells show upregulation of PI3K activity and EMT-related genes [8]. Differentially expressed EMT-, tumor metastasis- and Wnt signaling-related genes in 
Fig. $2 \mathrm{BMP} 7 \mathrm{v}$ treatment promotes $\mathrm{CR}-\mathrm{CSC}$ differentiation. a Phasecontrast microscopy analysis of $\mathrm{CD} 44 \mathrm{v}^{+} \mathrm{CRC}$ sphere cells treated with $B M P 7 v$ at the indicated time points. One representative of CSC\#1, 2, 4, 5, 7, and 23-26 is shown. The scale bar represents $20 \mu \mathrm{m}$. b Percentage of CK20 positive cells in $\mathrm{CD}_{4} \mathrm{vv}^{+}$CR-CSCs treated with vehicle or BMP7v up to 21 days evaluated by immunofluorescence analysis. Data are expressed as mean $\pm \mathrm{SD}$ of experiments performed in 15 CRC sphere cell lines (CSC\#1-3, 5-7, 10,11, 14-16, $18,25,33$, and 40). c Flow cytometry analysis of CD133/CD44v6 on CRC sphere cells treated with vehicle or BMP7v for 14 days. Data reported are mean $\pm \mathrm{SD}$ of $15 \mathrm{CRC}$ sphere cell lines analyzed (CSC\#1-8, 10,11, 14-16, 18, and 25). d (left panels) Immunofluorescence analysis of CDX2 on CR-CSCs upon 14 days of BMP7v treatment. One representative of CSC\# 3, 9, and 21 is shown. Nuclei were stained with Toto-3 (blue color). The scale bars represent $20 \mu \mathrm{m}$. (right panel) Percentage of CDX2 positive cells in CD44v6 ${ }^{+}$CR-CSCs treated with vehicle or BMP7v up to 14 days evaluated by immunofluorescence analysis. Data are expressed as mean \pm SD of experiments performed in CSC\# 3, 9, and 21. e Flow cytometry analysis of TOPdGFP or CD44v6 in enriched CD44v6 ${ }^{+}$sphere cells treated with BMP7v up to 14 days. One representative experiment of CSC\#1, 2, 4, 7 , and 10 is shown. f Phase-contrast microscopy analysis of TOPdGFP CRC sphere cells grown in matrigel drops and treated with vehicle, BMP7v or FBS for 14 days. One representative of CSC\# 8, 9, and 11 is shown. The scale bar represents $100 \mu \mathrm{m}$. g Immunofluorescence analysis of E-cadherin, vimentin, and $\beta$-catenin (green color) in $\mathrm{CD} 44 \mathrm{v} 6^{+} \mathrm{CRC}$ cells exposed to vehicle or BMP7 $\mathrm{v}$ for 14 days. One representative experiment performed in cells as in e is shown. Nuclei were stained with Toto-3 (blue color). The scale bars represent $20 \mu \mathrm{m}$. h Migrating CD44v6 ${ }^{+}$and CD44v6 $6^{-}$cells treated with vehicle or BMP7v up to $48 \mathrm{~h}$. Data are shown as mean \pm SD of three independent experiments performed in five CRC sphere cell lines (CSC\#1, 5, 7, 10, and 12). i Cell viability percentage of enriched $\mathrm{CD} 44 \mathrm{v} 6^{+}$and $\mathrm{CD} 44 \mathrm{v} 6^{-}$cells treated with vehicle or BMP7v up to $96 \mathrm{~h}$. Data are shown as mean $\pm \mathrm{SD}$ of different experiments performed in CSC\#1, 2, 4, 7, and 10. $\mathbf{j}$ Cell cycle analysis in CD44v6 ${ }^{+}$CR-CSCs exposed to vehicle or BMP7v for $72 \mathrm{~h}$. The data show percentage of cell number in sub-G0, G0/G1, S, and G2/M phases. Data are expressed as mean $\pm \mathrm{SD}$ of three independent experiments performed in five different CRC sphere cell lines as in e. $\mathbf{k}$ Immunoblot analysis of PARP, cleaved PARP (cPARP), Caspase-3 (Casp-3), cleaved Caspase-3 (cCasp-3), Bcl-2, Bcl-xL in CD44v6 ${ }^{+}$, and CD44v6 ${ }^{-}$ enriched cells treated as in e for $72 \mathrm{~h}$. $\beta$-actin was used as loading control. One representative experiment performed in three different CRC sphere cell lines (CSC\#1, 4, and 7)

CD44v6 ${ }^{-}$cell compartments (Fig. 3b) were comparable with those in CD44v6 ${ }^{+}$CRC cells treated with BMP7v (Fig. 3c), in line with the ability of this compound to turn CD44v6 ${ }^{+}$CSCs into CD44v6 ${ }^{-}$differentiated cells. Specifically, BMP7v induced the upregulation of 7 genes and the downregulation of other 48 genes in both CD44v6 cells and CD44v6 ${ }^{+}$cell fractions. Of note, the gene set enrichment analysis (GSEA) performed with the molecular signatures database (MSigDB) revealed the activation of programs associated with differentiation and attenuation of EMT and metastatic biological processes (Fig. 3d, e and Supplementary Fig. 4a, b). The most relevant downregulated and upregulated genes were further validated by RT-PCR (Fig. 3f). Thus, BMP7v forces CD44v6 ${ }^{+}$CRCSCs towards a more differentiated phenotype.
BMP7v potentiates the effects of standard therapy in naive and chemoresistant CR-CSCs

Following a dose-escalation delivery in vivo, we selected for subsequent studies the $50 \mu \mathrm{g} / \mathrm{kg}$ dose of BMP7v, which reduced significantly tumor growth while being well tolerated (Supplementary Fig. 5a). Of note, BMP7v alone exerted an antiangiogenic effect in xenograft tumors generated by the injection of CR-CSCs. Unlike BMP4, BMP7v treatment induced a fivefold increase in necrosis (Fig. 4a, b) and significantly reduced the number of microvessels in CR-CSCbased mouse avatars, as assessed by CD31 and VEGFR2 detection (Fig. 4c, d). In order to test whether BMP7v could sensitize CR-CSCs resistant to conventional therapy, we investigated the in vitro effect of $\mathrm{BMP} 7 \mathrm{v}$ in combination with a standard chemotherapy regimen.

About half of the examined CR-CSC lines showed $>50 \%$ survival after $24 \mathrm{~h}$ of in vitro treatment with oxa plus 5-FU (Fig. 4e). Based on the functional characterization of chemotherapy response, we selected four primary CR-CSC lines, derived from metastatic liver lesions of patients progressing after chemotherapy treatment (R1-R4), and three CR-CSC lines (CSC\#1, 2, and 7) showing different degrees of chemoresistance. Of note, BMP7v was able to render R-CSCs sensitive to oxa plus 5-FU in vitro treatment, the same therapeutic regimen completely ineffective in vivo in the metastatic patients from which these cells were derived (Fig. 4f).

The ability to form colonies was significantly compromised in CR-CSCs in the presence of BMP7v in combination with oxa plus 5-FU in vitro (Fig. $4 \mathrm{~g}$ ). This treatment affected both the in vitro self-renewal and the in vivo tumorigenic capacity of subcutaneously injected CR-CSCs. While tumor xenografts generated by the injection of $\mathrm{CSC \#} 2$ and 7 were sensitive to the combined treatment of $\mathrm{BMP} 7 \mathrm{v}$ and chemotherapy, PIK3CA-mutant tumor xenografts derived from the implantation of CSC\#1 delayed the outgrowth showing a kinetic trend similar to that of tumors treated with vehicle (Fig. 4h). Immunohistochemical analysis of xenograft tumors (CSC\#7) treated with BMP7v and chemotherapy showed a reduction of CD44v6, nuclear $\beta$-catenin, and Ki67 expressing cells, together with a concomitant increase in CK20 positive cells (Fig. 4i). Interestingly, xenograft tumors treated with chemotherapy alone showed a significant increase of cells expressing CD44v6 and nuclear $\beta$-catenin accompanied with a decrease of Ki67 positive cells. Thus, BMP7v sensitizes both naive and chemoresistant CR-CSCs to standard therapies.

\section{BMP7v enhances the therapeutic response to PI3K inhibitors and reduces the size of PIK3CA-mutant xenograft tumors}

We next investigated whether the addition of PI3K inhibitors to BMP7v-based therapy could represent an 


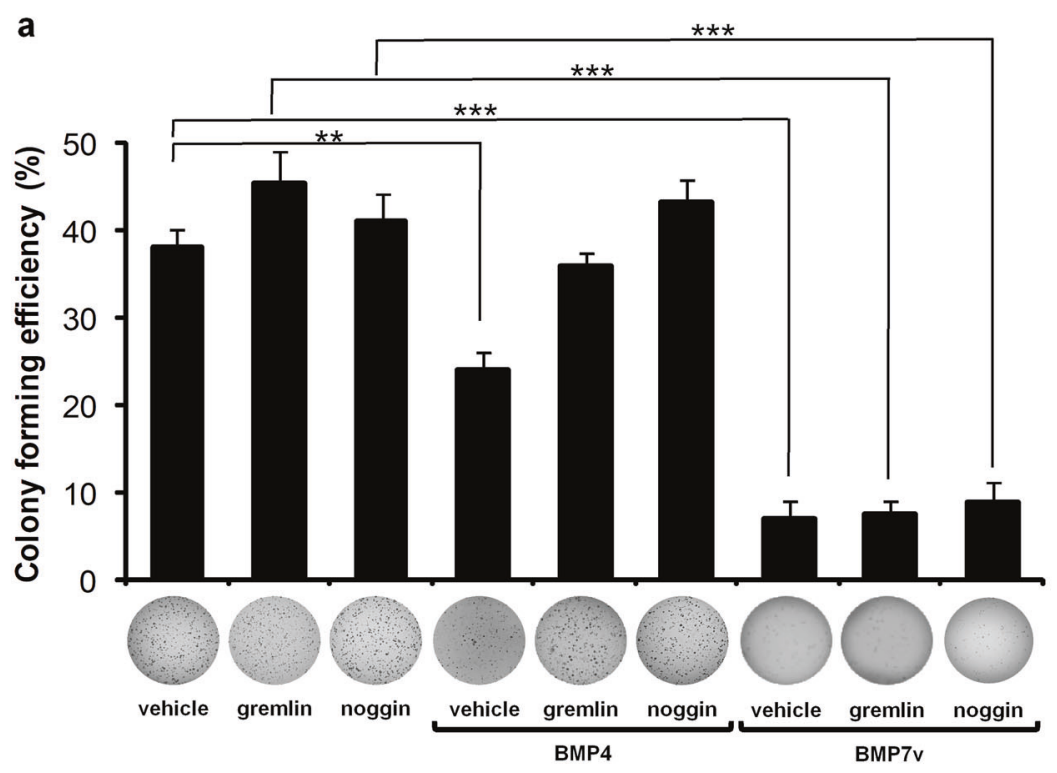

b
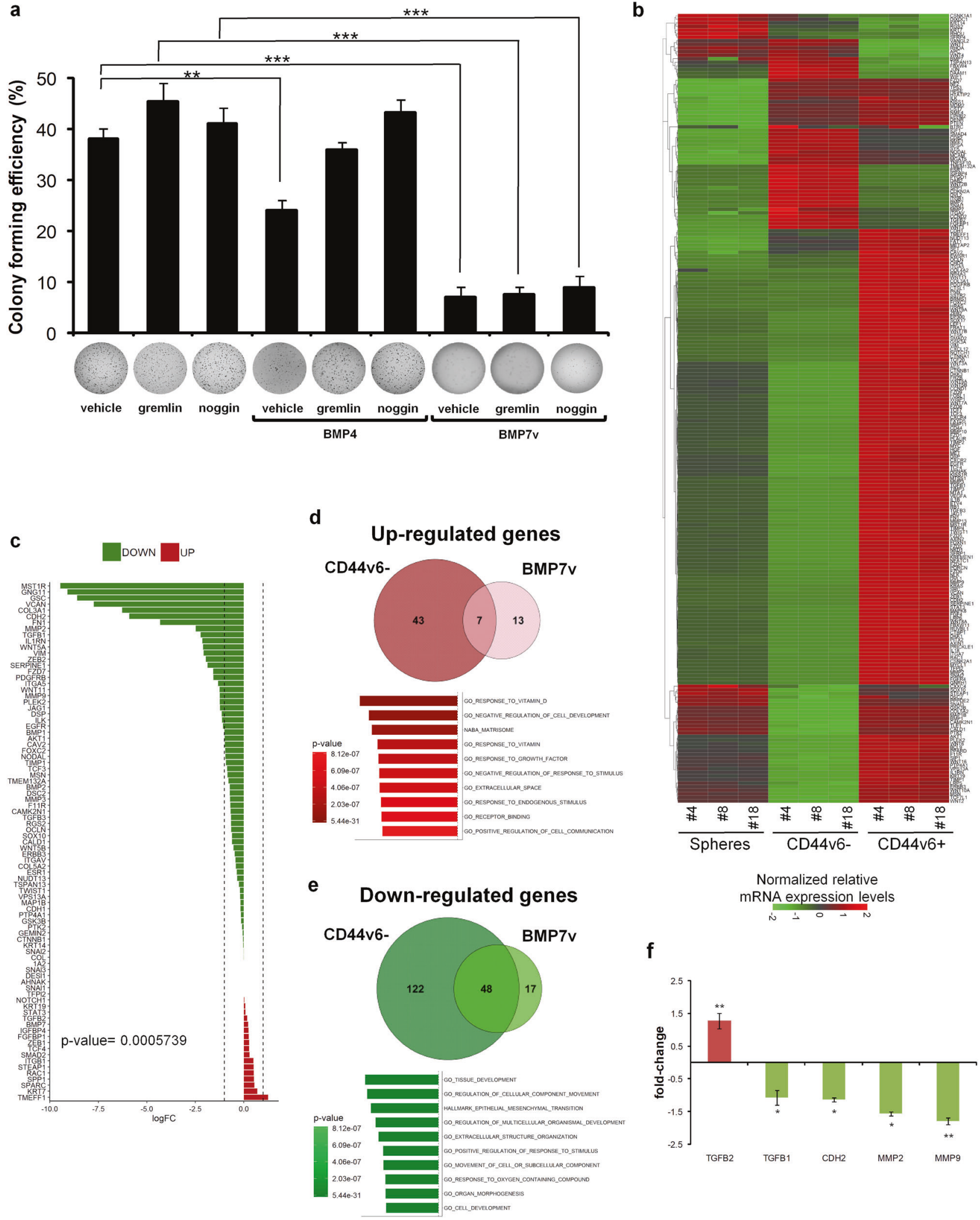

f

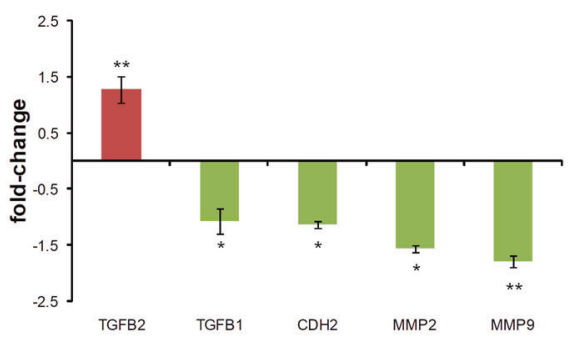

efficacious approach in the CD44v6 $6^{+}$cells, particularly in the presence of PIK3CA mutation. We first observed that in vitro $\mathrm{BMP} 7 \mathrm{v}$ treatment attenuated the PI3K/AKT pathway in $\mathrm{CD} 44 \mathrm{v} 6^{+}$cells, whose expression levels became similar to those exhibited by CD44v6 $6^{-}$compartment (Fig. 5a and Supplementary Fig. 5b). Then we found 
Fig. $3 \mathrm{BMP} 7 \mathrm{v}$ hampers the self-renewal and recapitulates a CD44v6--like cell subpopulation profile. a Colony forming efficiency percentage of CD44v6 ${ }^{+}$CR-CSCs treated for 14 days with vehicle, gremlin or noggin alone or in combination with BMP4 or BMP7v. Data are reported as mean $\pm \mathrm{SD}$ of five different $\mathrm{CRC}$ sphere cell lines analyzed (CSC\#1, 2, 4, 7, and 10). Representative soft-agar analysis is shown in the lower part of graph. b Heat map of EMT-, tumor metastasis-, and Wnt pathway-related genes $\left(2^{-\Delta \Delta C t}\right.$ expression values) in spheres, $\mathrm{CD} 44 \mathrm{v6}^{-}$and $\mathrm{CD} 44 \mathrm{v6}^{+}$cells. Data are presented as normalized expression values of three different CRC sphere cell lines (CSC\#4, 8, and 18). $\mathbf{c}$ Log fold change ( $\log F C$ ) values of differentially expressed related genes in enriched $\mathrm{CD} 44 \mathrm{v} 6^{+}$cells treated with $\mathrm{BMP} 7 \mathrm{v}$ for 3 days. Data are presented as the average of normalized mRNA expression levels of four different CR-CSC lines (CSC\#1, 3, 5, and 7). Dotted lines represent -1 and $1 \operatorname{logFC}$ values. $P$ value indicates difference between normalized mRNA expression levels of untreated vs BMP7 $v$ treated samples. d Venn diagram showing upregulated (red) and e downregulated (green) genes in CD44v6 ${ }^{-}$and BMP7v treated cells. (Lower panels) Top ten significantly enriched gene sets (FDR $q$ value $\leq 0.05$ ), selected by using Hallmark, KEGG, and GO, related to the indicated 7 up- and 48 down-regulated genes common in CD44v6 $6^{-}$ cells and CD44v6 $6^{+}$cells treated with BMP7v. $P$ values related to each enriched gene set are indicated. $\mathbf{f}$ Fold change values of the differentially upregulated (red) and downregulated (green) genes further validated by RT-PCR in CR-CSCs upon treatment with BMP7v for $72 \mathrm{~h}$. Data are expressed as mean $\pm \mathrm{SD}$ of experiments performed in CSC\# 1, 3, 9, and 21

that BMP7v combined with a PI3K inhibitor (taselisib) was also able to revert the intrinsic chemotherapy resistance of CR-CSCs in vitro (Fig. 5b). Following the integration of the dose-response and synergy score evaluation from Bliss and ZIP algorithms, $100 \mathrm{ng} / \mathrm{ml}$ of BMP7v and $1 \mu \mathrm{M}$ of PI3K inhibitor (taselisib) were selected for in vitro therapeutic combination (Supplementary Fig. 5c). Thus, to render PIK3CA-mutant CR-CSCs-derived avatars more sensitive to the combination therapy, we decided to inhibit the PI3K activity concomitantly. As expected, BMP7v in combination with taselisib significantly reduced the size of tumor xenografts generated by the injection of PIK3CAmutated CR-CSCs (Fig. 5c), suggesting the necessity to simultaneously add a PI3K inhibitor in the presence of enhanced activation of the PI3K/AKT pathway. To determine whether the addition of BMP7v to PI3K inhibitor, taselisib could also induce regression of the disease, metastatic mouse avatars generated by the injection of PIK3CA-mutated CR-CSCs into NOD-SCID mice spleen, were treated 4 weeks after the splenectomy once the metastatic lesions were detectable. The combination of $\mathrm{PI} 3 \mathrm{~K}$ and BMP7V significantly lessened the size of metastatic lesions of PIK3CA-mutated CR-CSCs, even 4 weeks after treatment suspension (Fig. 5d-f). The majority of CD44v6 $6^{+}$cells found in the liver and lung metastases of mice treated with the PI3Ki-BMP7v combination therapy underwent cell death, confirming the potential clinical application of this therapeutic approach in patients with metastatic CRC (Fig. 5g, h). Altogether, these findings suggest that BMP7v can turn CD44v6 ${ }^{+}$cells into a therapy sensitive $\mathrm{CD} 44 \mathrm{v6}^{-}$differentiated phenotype. Although PIK3CA-mutated CR-CSCs are less sensitive to the prodifferentiation activity of BMP7 signaling, the addition of a PI3K inhibitor restores their sensitivity in established tumors (Fig. 6a).

\section{Discussion}

We previously demonstrated that CD44v6 is a functional receptor that identifies migrating CSCs able to develop CRC metastasis [8]. Here, we show that CD44v6 enriched CR-CSCs lack the expression of BMP7, which is conversely confined within the differentiated counterpart (CD44v6 ${ }^{-}$cells). The heterogeneous expression of BMP7 within the CD44v6 $6^{-}$compartment is likely due to the presence of progenitor cells $\left(\mathrm{CD} 44 \mathrm{v} 6^{-} / \mathrm{CD} 133^{+}\right.$cells) endowed with residual $\beta$-catenin activation, which renders these cells reprogrammable by the microenvironmental cytokines [8]. Here, we show that BMP7 expression represents an early event in $\mathrm{CRC}$ as confirmed by its presence in colon adenoma and adenocarcinoma. Moreover, its expression inversely correlated with the pathological grading of CRCs, again supporting the association between this morphogen and differentiated tumor. In accordance with the reported effects in glioma stem cells [41], BMP7v induce the expression of differentiation markers in CR-CSCs, which gradually reduce their $\beta$-catenin activity and CD44v6 expression. We previously reported that BMP4 promotes differentiation and affects the self-renewal activity of CR-CSCs [24]. Through a SMAD1/4-mediated epigenetic mechanism, BMP4 leads to the recruitment of histone deacetylase HDAC1 and consequent transcriptional suppression of stemness genes [42]. Accordingly, targeting the Wnt pathway by BMP7v curtails the clonogenic activity of CD44v6 ${ }^{+} \mathrm{CRC}$ cells and leads to their terminal differentiation, as highlighted by the presence of PARP activation and downregulation of the antiapoptotic proteins Bcl-2 and Bcl-xL. The similar trend of cell viability in both $\mathrm{CD} 44 \mathrm{v} 6^{+}$and $\mathrm{CD} 44 \mathrm{v} 6^{-}$populations is likely due to the presence, in the CD44v6 $6^{-}$fraction, of progenitor cells that are affected by the BMP7v treatment. Tumor microenvironment reprograms cancer cells towards an EMT process leading them to acquire a more pronounced self-renewal and migratory phenotype [8, 43]. We have shown that cytokines released by cancerassociated fibroblasts are able to dedifferentiate CD44v6 cells into $\mathrm{CD} 44 \mathrm{v} 6^{+}$metastatic $\mathrm{CR}-\mathrm{CSCs}$, with the induction of a number of EMT genes [8]. BMP7v drives CRCSCs to behave similarly to the differentiated CD44v6 cells by downregulating the majority of EMT-related genes, which are needed by $\mathrm{CD} 44 \mathrm{v} 6^{+}$cells to retain an 
a

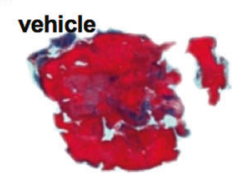

BMP7v

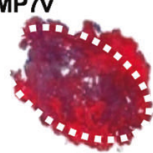

d

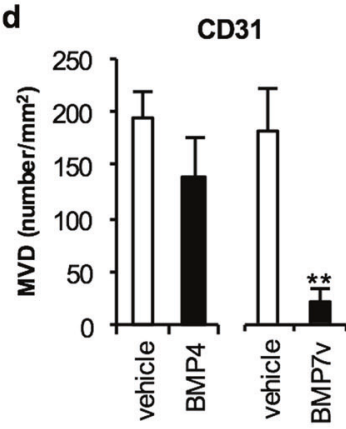

f

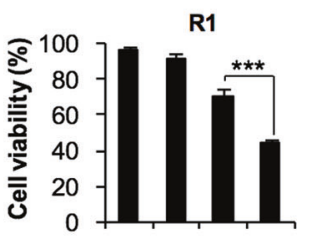

R3

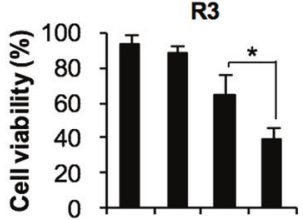

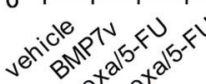
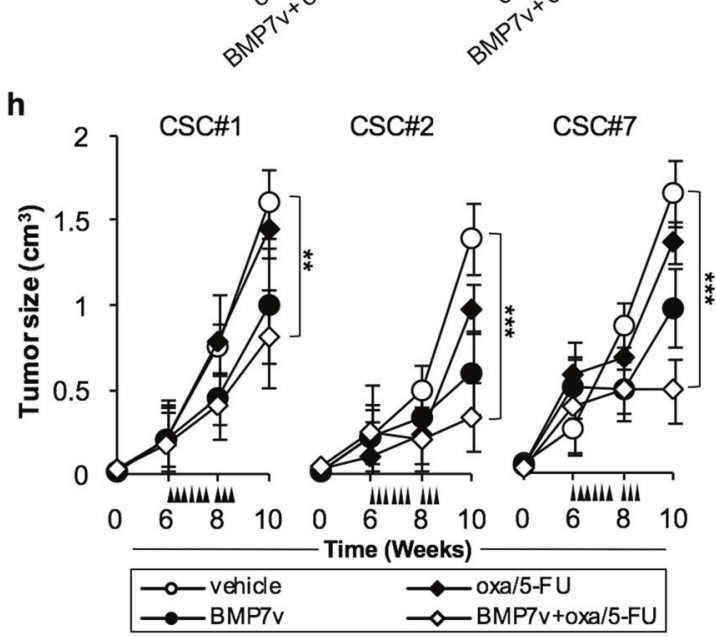

aggressive phenotype. We previously demonstrated that BMP4 induces PTEN upregulation and inhibition of PI3K/ AKT [24], which sustains the stem-like cell properties of

e
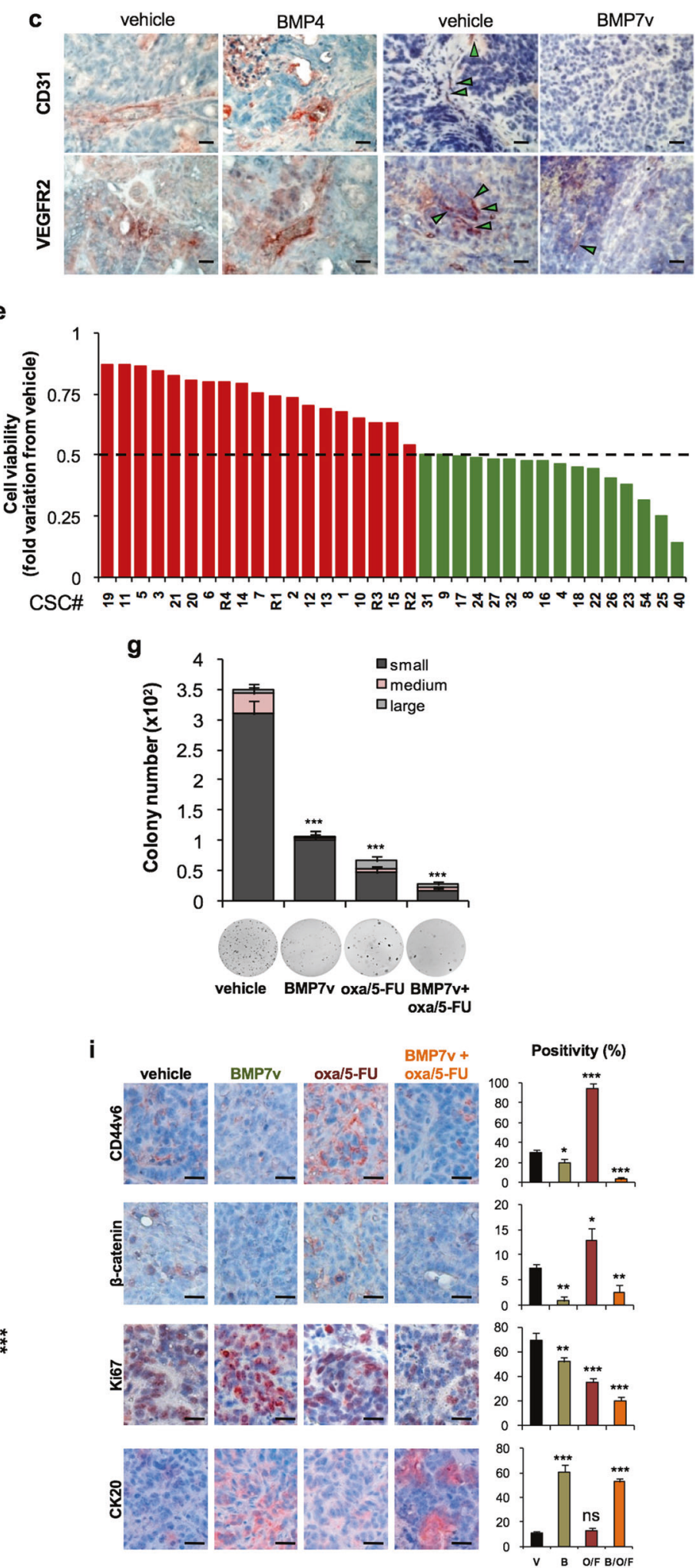

CD44v6 ${ }^{+}$CR-CSCs [8]. BMP7v displays a similar inhibition on the PI3K/AKT pathway. Here, we have shown that even though PTEN increased moderately upon 
Fig. $4 \mathrm{BMP} 7 \mathrm{v}$ exerts antiangiogenic effects and sensitizes chemoresistant CSCs to standard therapy. a Azan-Mallory staining on paraffinembedded sections of xenografts derived from the injection of CRC sphere cells and treated for 4 weeks (6-9 weeks) with PBS (vehicle) or BMP7v. Data are representative of three independent experiments using different CRC sphere cell lines (CSC\#2, 7, and 18). b Percentage of necrosis evaluated on paraffin-embedded sections of xenografts treated as in a. Data are shown as mean $\pm \mathrm{SD}$ of three independent experiments. c Immunohistochemical analysis of CD31 and VEGFR2 (red staining) on paraffin-embedded sections of xenografts generated by the injection of CRC sphere cell lines and treated with PBS (vehicle), BMP4, or BMP7v. Green arrowheads indicate microvessels expressing CD31 or VEGFR2. Images are representative of three independent experiments using cells as in $\mathbf{a}$. Nuclei were revealed by hematoxylin staining (blue). The scale bar represents $20 \mu \mathrm{m}$. d Number of microvessels positive for CD31 (left panel) and VEGFR2 (right panel) expression, evaluated on paraffin-embedded sections of xenografts treated as in c. Data are shown as mean \pm SD of cells. MVD $=$ microvessel density. e Fold change of viable cells in 35 CR-CSC lines treated with oxaliplatin/5-FU for $24 \mathrm{~h}$. Dotted line indicates the threshold between chemoresistant (red) and sensitive CR-CSCs (green). f Cell viability percentage in chemoresistant CR-CSCs (R1R4) pretreated with BMP7 for 3 days and with oxaliplatin/5-FU (oxa/ 5 -FU) for additional $24 \mathrm{~h}$ as indicated. Data are shown as mean $\pm \mathrm{SD}$ of three different experiments performed in the indicated R-CSCs. g Colony forming efficiency of CR-CSCs treated as in $\mathbf{f}$ and evaluated at 21 days. Representative soft-agar analyses are reported in the lower part of the graph. Bars show the mean $\pm \mathrm{SD}$ of seven different CRC sphere cell lines (CSC\#1-3, 5, 7, 10, and 18). h Tumor size of subcutaneous growth of the indicated CR-CSCs. Mice were treated for 4 weeks (6-9 weeks) with vehicle, oxaliplatin/5-FU (oxa/5-FU) and BMP7 $\mathrm{v}$ alone or in combination. Error bars show the mean \pm SD of tumor size measured in six mice/group. Black arrowheads indicate days of treatment. i Immunohistochemical analysis of CD44v6, $\beta$-catenin, Ki67, and CK20 (red color) in paraffin-embedded sections of CSC\#7 xenografts treated as in $\mathbf{h}$. Nuclei were counterstained by aqueous hematoxylin (blue color). The scale bar represents $20 \mu \mathrm{m}$ (left panels). Percentage of CD44v6, $\beta$-catenin, Ki67, and CK20 positive cells in paraffin-embedded sections of tumor xenografts treated with vehicle $(\mathrm{V}), \mathrm{BMP} 7 \mathrm{v}(\mathrm{B})$, oxaliplatin/5-FU $(\mathrm{O} / \mathrm{F})$, alone or in combination $(\mathrm{B} / \mathrm{O} / \mathrm{F})$ for $72 \mathrm{~h}$. Error bars are mean $\pm \mathrm{SD}$ of positive cell counts in three serial embedded-paraffin sections of six tumor xenografts per group derived from the injection of three different CRC sphere cells (CSC\#1, 2, and 7) (right panels)

BMP7v treatment, PI3K protein expression, and AKT activation levels decreased significantly in $\mathrm{CD} 44 \mathrm{v} 6^{+}$cells, which differentiate and revert to $\mathrm{CD} 44 \mathrm{v} 6^{-} / \mathrm{PI} 3 \mathrm{~K}^{\text {low }}$ cells. This mechanism is in line with the observation that the natural compound resveratrol inhibits the PI3K pathway by upregulating the BMP7 in human colon cancer cells [44]. The induction of differentiation may represent an alternative therapeutic approach to render CSCs sensitive to standard therapies [24, 45]. Differentiation therapy is currently in phase 2 clinical trial for the cure of acute promyelocytic leukemia [46]. The expression of antiapoptotic genes and the upregulation of survival factors contribute to CSC resistance to conventional anticancer therapies [32].

BMP7v reduces the expression levels of anti-apoptotic proteins and makes PIK3CA wt CRC avatars sensitive to standard chemotherapy. In addition, BMP7v enhances the therapeutic response even against CR-CSCs purified from metastatic lesions of patients who underwent chemotherapy. About $10-30 \%$ of CRCs exhibit PI3K activation sustained by PIK3CA mutations, which contribute to confer resistance to standard therapies and targeted agents [47]. PIK3CA-mutated tumor xenografts display resistance to the combination of BMP7v and chemotherapy. This is not surprising because it is likely that the increased $\beta$-catenin activation promoted by the constitutive activation of PI $3 \mathrm{~K}$ counteracts the inhibitory activity on the Wnt pathway induced by BMP signaling.

$\mathrm{PI} 3 \mathrm{~K}$ is a target for pharmacological drug design and therapeutic intervention in many cancers, including CRC [48]. Nowadays, although PI3K inhibitors have a limited effect as single agents in CRC, several clinical trials are exploring the efficacy of these inhibitors in different combinatorial treatments $[47,49]$. Here we showed that BMP7 $\mathrm{v}$ is able to sensitize chemoresistant CR-CSCs to PI3K inhibitors in vitro regardless their MSI and CMS profiles. Addition of a PI3K inhibitor to the combination of BMP7 $\mathrm{v}$ and chemotherapyinduced tumor regression of PIK3CA-mutant tumor xenograft, further supporting the potential clinical application of this combination therapy. In line with our previous findings, PI3K inhibitors alone selectively target disseminating CRCSCs [8], whereas in combination with BMP7 $\mathrm{v}$ treatment induce disease regression by reducing the size of both primary tumors and established CRC liver metastasis.

In conclusion, we have shown that BMP7 $v$ exerts a potent antitumor activity through the induction of differentiation of PIK3CA wt CR-CSCs. Although the presence of PIK3CA mutation reduces the therapeutic activity of $B M P 7 \mathrm{v}$, we provide evidence that the addition of PI $3 \mathrm{~K}$ inhibitors may be sufficient to restore CR-CSC sensitivity to BMP7v. Unlike BMP4, BMP7 $v$ exerts a significant antiangiogenic effect and can be administered systemically, due to its solubility and prolonged half-life, which also facilitate its combination with standard chemotherapy or targeted agents. Further studies are needed to investigate the minimal residual disease upon the combination therapy based on BMP7v and PI3K inhibitor.

Because the efficacy of targeted therapy is limited by the presence of intratumor heterogeneity, this prodifferentiation approach coupled with such a considerable antiangiogenic activity may contribute to overcome the hurdles of dynamic tumor changes. Thus, BMP7v-based combination therapies may represent potential novel treatment options for CRC.

\section{Materials and methods}

\section{Isolation and treatment of CR-CSCs}

Human CRC tissues were obtained from 40 patients at the time of resection, in accordance with the ethical standards of 

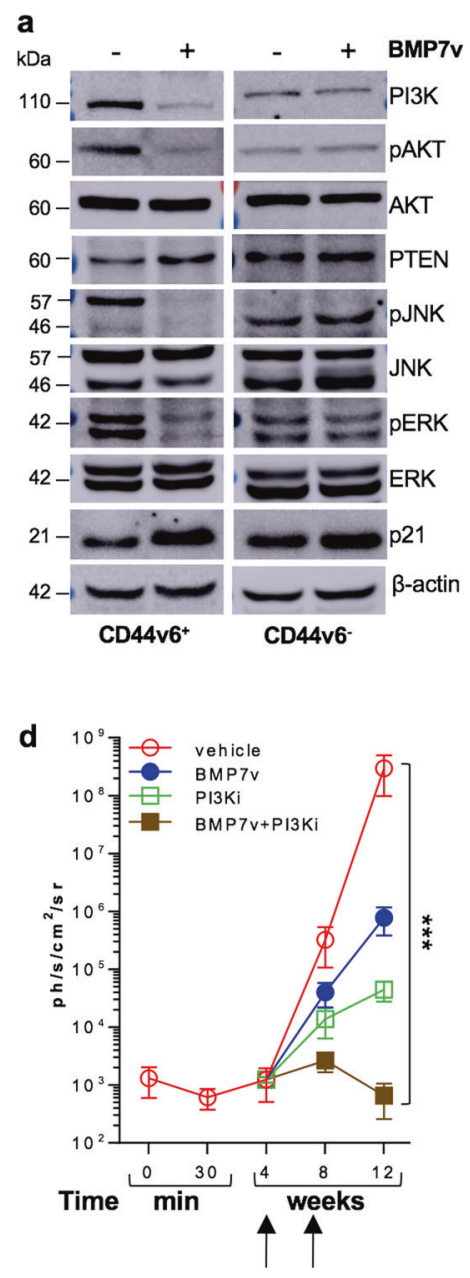

f

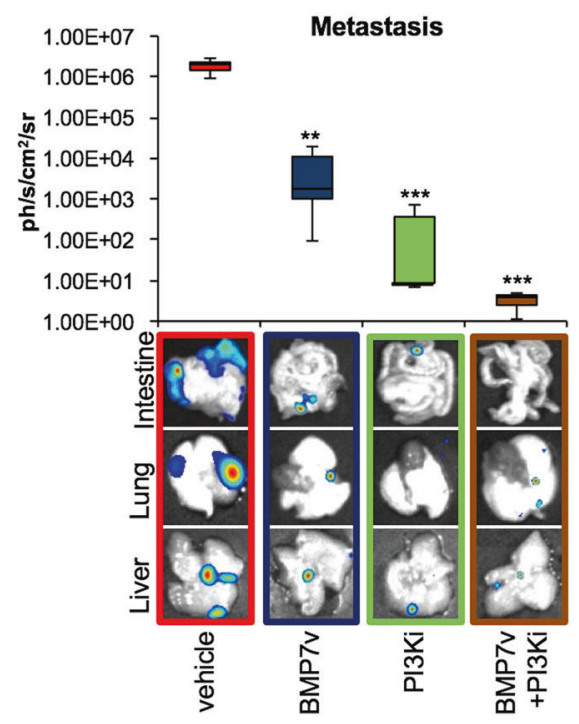

the Institutional Committee on Human Experimentation (authorization CE9/2015, Policlinico Paolo Giaccone, Palermo) after informed consent. Peritumoral mucosa was
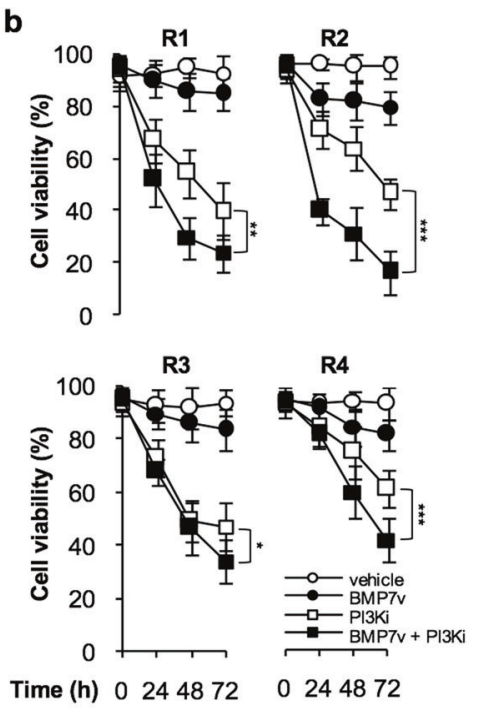

c

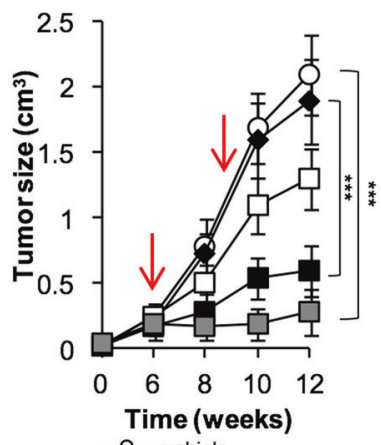

$\longrightarrow$ oxals-Fu

- $-\mathrm{PI} 3 \mathrm{Ki}$

-BMP7V+PI3Ki

$\because$-BMP7v+PI3Ki+oxa/5-FU

e
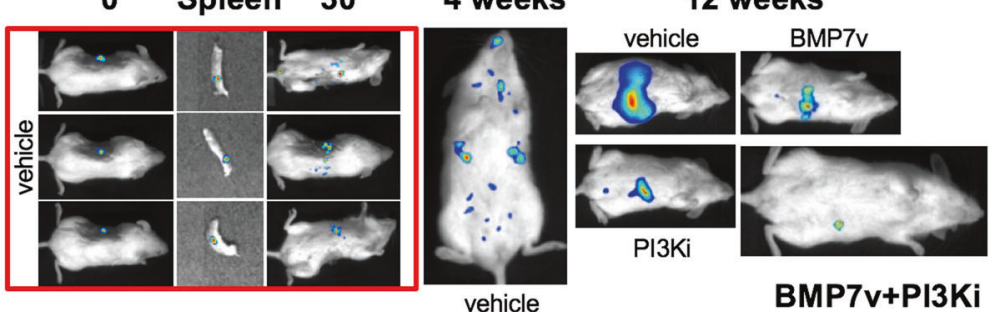

BMP7v+PI3Ki

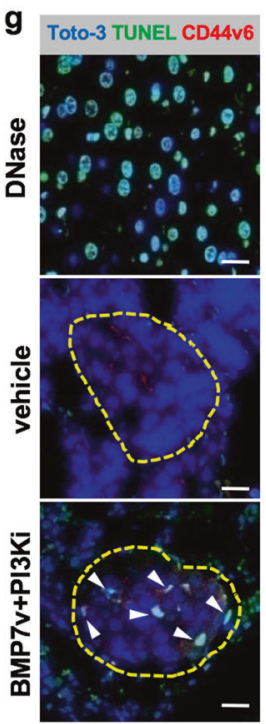

h

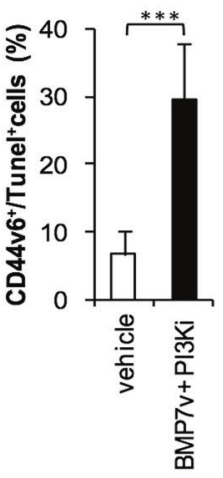

recovered from the uninvolved surrounding tumor tissue. Clinical data of CRC patients from which CRC sphere cell lines were derived are reported in Supplementary Table 1. 
Fig. $5 \mathrm{BMP} 7 \mathrm{v}$ in combination with $\mathrm{PI} 3 \mathrm{~K}$ inhibitor hampers tumor growth and reduces the metastatic lesion size. a Immunoblot analysis of PI3K, pAKT, AKT, PTEN, pJNK, JNK, pERK, ERK, and p21 in $\mathrm{CD}_{4} 4 \mathrm{v} 6^{+}$and $\mathrm{CD} 44 \mathrm{v} 6^{-}$cells treated with vehicle or $\mathrm{BMP} 7 \mathrm{v}$ for 3 days. $\beta$-actin was used as loading control. One representative of three independent experiments (CSC\#1, 4, and 7) is shown. b Cell viability percentage in R-CSCs treated with vehicle, BMP7v, PI3K inhibitor (PI3Ki), or BMP7v in combination with PI3K inhibitor $(\mathrm{BMP} 7 \mathrm{v}+$ $\mathrm{PI} 3 \mathrm{Ki}$ ) up to $72 \mathrm{~h}$. Data are shown as mean \pm SD of three different experiments performed with the indicated R-CSCs. c Tumor size of subcutaneous outgrowth of PIK3CA-mutated xenografts. Mice were treated with vehicle, PI3K inhibitor (PI3Ki), oxaliplatin/5-FU (oxa/5$\mathrm{FU}), \mathrm{BMP} 7 \mathrm{v}$ in combination with PI3K inhibitor (BMP7v + PI3Ki) or BMP7 in combination with $\mathrm{PI} 3 \mathrm{~K}$ inhibitor and oxaliplatin/5-FU $(\mathrm{BMP} 7 \mathrm{v}+\mathrm{PI} 3 \mathrm{Ki}+\mathrm{oxa} / 5-\mathrm{FU})$. Data are shown as mean $\pm \mathrm{SD}$ of tumor size of six mice/group using CSC\#1, 18, and 25. Red arrows indicate the start and the end (from 6 to 9 weeks) of treatments. d Kinetics of metastasis formation detected by in vivo imaging analysis at the indicated time following spleen injection of CSC\#1, 18, and 25 treated with vehicle, BMP7v, PI3K inhibitor (PI3Ki), or BMP7 $v$ in combination with PI3K inhibitor (BMP7 $v+$ PI3Ki) for 4 weeks. Black arrows indicate the start and end of treatments (from 4 to 7 weeks). Data are expressed as mean \pm SD of six mice analyzed. e In vivo whole-body imaging analysis of mice treated as in $\mathbf{d}$ and analyzed at the indicated time points after splenectomy. f Photons count of all metastatic sites (liver, lung, and intestine) in mice treated as in $\mathbf{d}$. Error bars are reported as mean $\pm \mathrm{SD}$ of the xenografts analyzed as in $\mathbf{d}$ (upper panel). Representative in vivo imaging analysis of metastatic foci in the liver, lung, and intestine of mice treated as indicated (lower panels). g Immunofluorescence analysis of CD44v6 (red color) and TUNEL (green color) in paraffin-embedded sections of lung metastasis generated by the injection of CSC\#25 in mice treated with vehicle or BMP7 $v+$ PI3K inhibitor $(\mathrm{BMP} 7 \mathrm{v}+\mathrm{PI} 3 \mathrm{Ki})$. White arrowheads indicate $\mathrm{CD} 44 \mathrm{v} 6{ }^{+} /$Tunel $^{+} \mathrm{CRC}$ cells. Nuclei were counterstained with Toto-3 (blue color). Positive control was performed treating cells with DNase. The scale bars represent $20 \mu \mathrm{m}$. h Percentage of CD44v6 ${ }^{+} /$Tunel $^{+}$cells of lung metastasis treated with vehicle or BMP7v + PI3K inhibitor (BMP7v + PI3Ki). Data are mean \pm SD of xenografts derived from injection of three different cell lines (CSC\#1, 18 , and 25)

CRC sphere cells were isolated and propagated as previously described [8, 32]. Briefly, specimens were digested in DMEM medium supplemented with $10 \mu \mathrm{g} / \mathrm{ml}$ of hyaluronidase (Sigma) and $0.6 \mathrm{mg} / \mathrm{ml}$ of collagenase (Gibco) for $1 \mathrm{~h}$ at $37^{\circ} \mathrm{C}$, resuspended in serum-free stem cell medium comprising EGF (Peprotech) and FGF2 (Peprotech) and cultured in ultra-low adhesion flasks. To generate SDACs, CR-CSCs were dissociated and then cultured in DMEM-high glucose supplemented with $10 \%$ FBS in adherent conditions up to 21 days [24]. Gradual morphological differentiation was determined by counting of cells in adherent conditions normalized with the number of CR-CSCs in suspension. To evaluate differentiation of CRC organoids, CR-CSCs were dissolved in a 1:10 stem cell medium/Matrigel solution, placed in a $24-w e l l$ plate as a single drop covered by medium and monitored twice a week up to 21 days.

Authentication of CRC sphere cell lines was assessed by short tandem repeat (STR) DNA profiling (GlobalFiler ${ }^{\mathrm{TM}}$

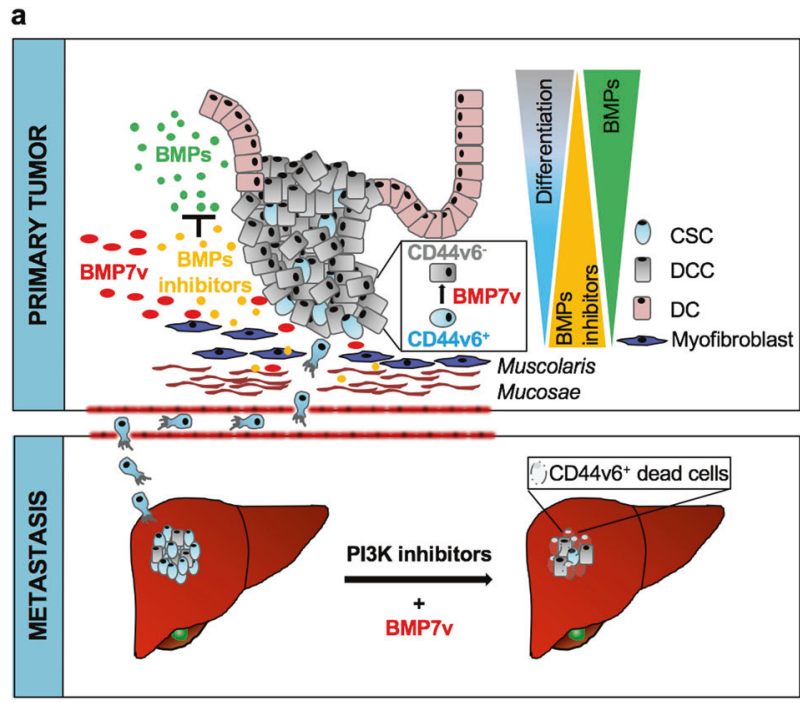

Fig. 6 Schematic model of BMP7v effects in primary and metastatic CRC. a In primary tumor the colon cancer crypt organization, which is physiologically maintained by BMPs/BMP inhibitor balance, is disrupted. The administration of $B M P 7 v$ selectively counteracts the expansion of the CSC compartment by reducing CD44v6 expression. Moreover, BMP inhibitors (noggin, gremlin, and others), produced by myofibroblasts, are not able to inhibit BMP7 $\mathrm{v}$ activity on promoting the differentiation of CSCs (upper panel). In metastatic tumor, BMP7v in combination with PI3K inhibitors reduces the number of $\mathrm{CD} 44 \mathrm{v} 6^{+}$ cells and hampers the tumor metastatic growth (bottom panel). CSC cancer stem cell, DCC differentiated cancer cell, DC differentiated cell

STR kit, Applied Biosystem) using the ABIPRISM 3130 genetic analyzer (Applied Biosystem) as recommended by the manufacturer's instructions. STR profiles of CRC sphere cells were matched with their relative patient-derived tumors. Primary cultures enriched in CSCs derived from chemoresistant metastatic liver lesions were obtained from patients undergoing hepatectomy with curative intent at the University Polyclinic A. Gemelli, Rome. Cell cultures were monitored for the presence of mycoplasma. CRC sphere cells and their enriched $\mathrm{CD} 44 \mathrm{v} 6^{+}$and $\mathrm{CD} 44 \mathrm{v} 6^{-}$fractions were treated with BMP7v (100 ng/ml produced by Eli Lilly as previously described) [30], gremlin (1 $\mu \mathrm{g} / \mathrm{ml}, \mathrm{R} \& D$ Systems), noggin (100 ng/ml, R\&D Systems), BMP4 (100 ng/ml, R\&D Systems), oxa (10 $\mu \mathrm{M}$, Selleckchem), 5-FU $(10 \mu \mathrm{M}$, Selleckchem), and taselisib (PI3Ki, $1 \mu \mathrm{M}$ GDC-0032, Chemietek). Oxa was added to cell culture media $2 \mathrm{~h}$ before 5 -FU treatment. All the compounds above described were added to cell culture media every $48 \mathrm{~h}$. BMP $7 \mathrm{v}$ dose was determined by the evaluation of colony forming efficiency in presence of different concentration of BMP inhibitors (gremlin and noggin), when in combination with PI3K inhibitor (taselisib) its effective dose was selected on the basis of CR-CSC viability. These experiments were conducted in SynergyFinder, including Bliss and ZIP, to calculate dose-response inhibition matrix and synergy scores [50]. 


\section{Immunohistochemistry and Immunofluorescence}

Immunohistochemistry analysis was performed on 5- $\mu \mathrm{m}$ thick paraffin-embedded sections of CRC tissues or CRC sphere cell-derived tumor xenografts. For intracellular epitope detection, tissue sections were permeabilized in ice-cold $0.1 \%$ TritonX-100 in PBS for $10 \mathrm{~min}$. Tissue samples were exposed overnight at $4{ }^{\circ} \mathrm{C}$ to specific antibodies for BMP7 (MAB3541, mouse, IgG2 $2_{\mathrm{b}}$, R\&D system), E-cadherin (\#3195, rabbit, IgG, CST), CD31 (M0823, clone JC70A, mouse $\mathrm{IgG1}_{\mathrm{k}}$, Dako), VEGFR2 (AF357, goat, IgG, R\&D System), CD44v6 (BBA13, clone $2 \mathrm{~F} 10$, mouse, IgG1, R\&D system), $\beta$-catenin (sc7199, rabbit, IgG, Santa Cruz Biotechnology), Ki67 (M7240, mouse, IgG1, DakoCytomation), and CK20 (NCL-L-CK20, mouse, IgG2 $2_{\mathrm{k}}$, Novocastra Leica). Primary antibodies were revealed by biotin-streptavidin peroxidase LSAB 2 Kit (Dako). Stainings were detected by using 3-amino-9- ethylcarbazole chromogen. Nuclei were counterstained with aqueous hematoxylin (Sigma).

For Azan-Mallory, tissues were stained with azocarmine $\mathrm{G}$ (Sigma) and 5\% of phosphoric acid. Then, sections were stained with a Mallory mix solution (Sigma). Staining was analyzed by using Imaging Analyzer Software.

Immunofluorescence staining was performed on paraffin-embedded sections, cells cytospun or cultured on coverslips. Cells were fixed in $2 \%$ paraformaldehyde for $20 \mathrm{~min}$ at $37^{\circ} \mathrm{C}$. Intracellular epitope detection was performed in cells permeabilized in $0.1 \%$ TritonX-100 in PBS for $10 \mathrm{~min}$. Following blocking with $3 \%$ bovine serum albumin (BSA) for $30 \mathrm{~min}$, cells were exposed overnight at $4{ }^{\circ} \mathrm{C}$ to BMP7 (MAB3541, mouse, IgG2 ${ }_{b}$, R\&D system), LGR5 (GPR49, rabbit, IgG, Abgent), CDX2 (MAB3665, mouse, IgG1, R\&D Systems), CK20 (NCL-L-CK20, mouse, $\mathrm{IgG} 2_{\mathrm{k}}$, Novocastra Leica), E-cadherin (\#3195, rabbit, IgG, CST), vimentin (\#5741, rabbit, IgG, CST), $\beta$-catenin (MAB1329, mouse, IgG2 ${ }_{b}, R \& D$ Systems), CD44v6 (BBA13, clone 2F10, mouse, IgG1, R\&D system), BMPR1A (MAB2406, mouse, IgG2 $2_{b}$, R\&D Systems), BMPR1B (MAB505, mouse, IgG2 ${ }_{a}, R \& D$ Systems) and, BMPR2 (MAB811, mouse, IgG2 ${ }_{\mathrm{b}}, \mathrm{R} \& \mathrm{D}$ Systems) antibodies or isotype-matched controls (IMCs). Primary antibodies were revealed using Alexa Fluor 488 or Rhodamine-conjugated anti-mouse or anti-rabbit secondary antibodies (Invitrogen) in the presence of RNase (40 $\mu \mathrm{g} / \mathrm{ml}$, Sigma). Nuclei were counterstained using Toto3 iodide (Molecular Probes).

Cell quantitation was performed by ImageJ Software analysis. Tunel assay was performed by using In Situ Cell Death Detection, AP Kit(Roche Diagnostics GmbH). DNA strand breaks were detected by 5-bromo-4-chloro-3-indolylphosphate (, Dako) substrate. DNase was used to perform the positive control.
TMAs were provided by TriStar Technology group (Tri), LLC, 9700 Great Seneca Highway, Rockville, MD 20850.

\section{Flow cytometry and cell cycle analysis}

CD133 and CD44v6 positive and negative subpopulations were obtained using FACS cell sorter (BD). Cells were stained for $1 \mathrm{~h}$ at $4{ }^{\circ} \mathrm{C}$ with CD133-PE (130-090-851, 293C3, mouse $\operatorname{IgG} 2_{\mathrm{b}}$, Miltenyi), CD44v6-APC (FAB3660A, clone 2F10, mouse, IgG1, R\&D systems) or corresponding IMCs IgG2b-PE (\#130-092-215, mouse, Miltenyi) or IgG1-APC (\#IC002A, mouse, R\&D systems). Before sorting, cells were resuspended in PBS supplemented with $2 \%$ BSA and $2 \mathrm{mM}$ EDTA, and strained through a $70 \mu \mathrm{m}$ mesh to avoid cell hindrance. Dead cells were excluded with 7-AAD (BD). Quality of postsorting was verified by flow cytometry using specific antibodies against CD133 (170-070-702, CD133/1-APC, AC133, mouse $\mathrm{IgG1}_{\mathrm{k}}$, Miltenyi) or CD44v6 (\#MA5-16966, CD44v6-FITC, VFF-7, mouse IgG1, Thermo Scientific). Cells were then washed twice in PBS, permeabilized with fixation/permeabilization solution (Cytofix/Cytoperm, BD) following the manufacturer's instructions and stained with BMP7-FITC (FCMAB135F, 2A10, mouse $\mathrm{IgG1}_{\mathrm{k}}$, Merck) or its IMC IgG1 $1_{k}$ (\#F6397, mouse, Sigma-Aldrich). For flow cytometry analysis of CD133 and CD44v6, PE(293C3) or APC-conjugated (2F10) clone were used, respectively. Cell cycle analysis was performed by quantification of DNA content on dissociated cells. Cells were incubated overnight at $4{ }^{\circ} \mathrm{C}$ in a buffer containing $50 \mu \mathrm{g} / \mathrm{ml}$ propidium iodide (Sigma-Aldrich), $0.1 \%$ sodium citrate (Sigma-Aldrich), $0.1 \%$ TritonX-100 and $10 \mu \mathrm{g} / \mathrm{ml}$ RNAse (Sigma-Aldrich). All data were analyzed using FlowJo software (Tree Star). The percentage of CD44v6 $6^{+}$cells has been assessed in all the $35 \mathrm{CRC}$ sphere cell lines and indicated as low $(<30 \%)$, medium $(30-70 \%)$, and high $(>70 \%)$ in Supplementary Table 2.

\section{Lentiviral particles generation and CR-CSC transduction}

To generate lentiviral particles, packaging cell line HEK$293 \mathrm{~T}$ were transfected with second-generation packaging plasmids (PSPAX2 and pMD2.G plasmids Addgene) in association with p-TWEEN LUC or TOP-dGFP (Addgene \# 35489) lentiviral vectors. Transfection was performed using X-tremeGENE HP DNA Transfection Reagent (Roche). Lentiviral supernatants were collected and concentrated with the Lenti-X Concentrator reagent (Clontech). $1 \times 10^{5}$ CRC sphere cells were transduced with concentrated viral supernatants for $24 \mathrm{~h}$ using $8 \mu \mathrm{g} / \mathrm{ml}$ polybrene. Wnt pathway activity was monitored by flow cytometry analysis on the basis of the TOP-dGFP expression levels. 


\section{Cell viability, clonogenic, and invasion assay}

The cell viability assay was performed using the CellTiter96 $6^{\circ}$ Aqueous One Solution Cell Proliferation Assay Kit (Promega) according to the manufacturer's instructions and examined with GDV programmable MPT reader (DV 990 BV6). For invasion assay, $2 \times 10^{3}$ dissociated CRCSCs were plated into $8 \mu \mathrm{m}$ pore size matrigel (BD)coated transwell and treated with vehicle or BMP7v up to $48 \mathrm{~h}$. Supernatant of NIH-3T3 cells cultured in serum-free medium was used as chemoattractant in the lower part of the transwell system. Migrating cells were examined and counted using an optical microscope. For clonogenicity, CR-CSCs were plated at a clonal density on Agarose Sea Plague Agar (Invitrogen) and maintained up to 21 days. Colonies were stained with $0.01 \%$ Crystal Violet, evaluated based on their size (small 30-60 $\mu \mathrm{m}$, medium 60-90 $\mu \mathrm{m}$, and large $>90 \mu \mathrm{m}$ ) and counted using ImageJ software.

\section{Western blot analysis}

Cell pellets were resuspended in ice-cold lysis buffer $(50 \mathrm{mM}$ Tris-HCL pH 8, $150 \mathrm{mM} \mathrm{NaCl}, 0.5 \%$ sodium deoxycholate, $0.1 \%$ SDS, $1 \%$ NP40, 1 mM EDTA) supplemented with a mix of protease and phosphatase inhibitors (Thermo Fisher Scientific). Equal amount of protein extracts was resolved on SDS-PAGE gels and blotted on nitrocellulose membranes. Membranes were exposed overnight at $4{ }^{\circ} \mathrm{C}$ to PARP (\#9524, rabbit, IgG, CST), Caspase-3 (\#9662, rabbit, IgG, CST), cleaved Caspase-3 (Asp175) (\#9661, rabbit, IgG, CST), Bcl-2 (sc-7382, mouse, IgG, Santa Cruz), Bcl-xL (sc8392, mouse, IgG, Santa Cruz), PI3K (p110 $\alpha$ ) (\#4249, C73F8, rabbit, IgG, CST), phospho-AKT (Ser473 XP) (\#4060, D9E, rabbit, IgG, CST), AKT (\#9272, rabbit, IgG, CST), PTEN (\#9559, 138G6, rabbit, IgG, CST), phosphoJNK (Thr183/Tyr185) (\#4668, 81E11, rabbit, IgG, CST), JNK (\#9258, 56G8, rabbit, IgG, CST), phospho-ERK (sc-7383, E-4, mouse, IgG2 a, Santa Cruz), ERK (sc-94, rabbit, IgG, Santa Cruz), p21 (\#2946, DCS60, mouse IgG2a, CST), and $\beta$-actin (\#3700, 8H10D10, mouse $\mathrm{IgG}_{\mathrm{b}}$, CST). Primary antibodies were detected using specific secondary HRP-conjugated antibodies (Thermo Fisher Scientific) and chemiluminescence signals were revealed using Amersham imager 600 (GE Healthcare). Protein expression levels were measured by densitometry analysis using ImageJ software.

\section{Mutation analysis and MSI profile}

Total DNA was purified from CR-CSCs using the Blood and Tissue Kit (QIAGEN). The mutational status of KRAS,
$B R A F$, PIK3CA, and SMAD4 genes was evaluated by the BigDye Terminator v3.1 Cycle Sequencing Kit (Applied Biosystems) using the following primers specific for $K R A S^{\mathrm{G} 12 / \mathrm{G} 13}$ (F-ATCGTCAAGGCACTCTTGCCTAC, R-G TACTGGTGGAGTATTTGATAGTG), $B R A F^{\mathrm{V} 600}$ (F-ACT CTAAGAGGAAAGATGAAG, R-GTGAATACTGGGAA CTATGA), $P I K 3 C A^{\mathrm{E} 545}$ (F-ATTGTTCACTACCATCCTC, R-TAATGTGCCAACTACCAATG) and $S M A D 4^{\mathrm{R} 361}$ (F-TG TGGAGTGCAAGTGAAAGC，R-TCAATGGCTTCTGTC CTGTG). Codon Code Aligner Software was used for sequence assembly and alignment. Assessment of MSI status of CR-CSCs was carried out using the GeneQuality CC-MSI kit (Analitica Advanced Biomedicine). Purified total DNA was subjected to a multiplex microsatellite PCR including mononucleotide repeats (BAT25, BAT26, BAT40, NR21, NR24, and TGFBRII) and dinucleotide repeats (D2S123, D17S250, D5S346, and D18S58). MSI analysis was carried out using GeneMapper 5.0 Software (Applied Biosystems). Samples were classified as MSI-high (four or more markers instable), MSI-low (1-3 markers instable), or MSS (microsatellite stable). Mutation and MSI profiles of CR-CSCs were performed on a Genetic Analyzer ABIPRISM 3130 (Applied Biosystems). COSMIC-reported mutations of $K R A S, B R A F, P I K 3 C A$, and SMAD4 in the 35 CRC sphere cell lines used and their MSI profiles are indicated in Supplementary Table 2 .

\section{RNA isolation and Real-time PCR}

Total RNA was obtained using the RNeasy Plus Mini Kit (Qiagen $\mathrm{GmbH}$ ) according to the manufacturer's instructions. The yield of the extracted RNA was determined by Nanodrop ND-1000 (Nanodrop, Wilmington, DE). One microgram of total RNA was retro-transcribed using the High-Capacity cDNA Archive Kit (Applied Biosystems) following the standard protocol. Quantitative real-time PCR analysis was performed in SYBR Green PCR master mix (SuperArray Bioscience) containing primers for BMPRIA (F-GTCATACGAAGATATGCGTGAGGTTGT, R-ATG CTGTGAGTCTGGAGGCTGGATT), BMPRIB (F-AAG GCTCAGATTTTCAGTGTCGGGA, R-GGAGGCAGTGTAGGGTGTAGGTCTTTATT), BMPR2 (F-GTGACT GGGTAAGCTCTTGCCGTCT, R-GCAGGTTTATAATG ATCTCCTCGTGGT), TGF $\beta 1$ (F- CTCGCCCTGTACA ACAGCA, R-GGTTTCCACCATTAGCACGC), TGF $\beta 2$ (ACAGACCCTACTTCAGAATTGTT, R-TGGGTTCTG CAAACGAAAGA) $\mathrm{CDH} 2$ (F- GGAGAACCCCATTGA CATTGT, R-TGTTCCAGGCTTTGATCCCT), $\quad M M P 2$ (TGGTGGGAACTCAGAAGGTG, R-CCACATCTTT CCGTCACTGC), MMP9 (F- ACTACTGTGCCTTT GAGTCC, R-CCAGTACTTCCCATCCTTGA), or GAPDH (F-GCTTCGCTCTCTGCTCCTCCTGT, R- 
TACGACCAAATCCGTTGACTCCG). Relative mRNA expression levels were normalized with the endogenous control $(G A P D H)$ and calculated using the comparative $\mathrm{Ct}$ method $2^{-\Delta \Delta \mathrm{Ct}}$. mRNA expression levels of EMT-, tumor metastasis-, and Wnt pathway-related genes were detected by $\mathrm{RT}^{2}$ profiler PCR array (PAHS-090, Qiagen) according to manufacturers' instructions. Data were analyzed using the $\mathrm{R}$ version 3.5.0 and plotted by the pheatmap version 1.0.10 and VennDiagram 1.6.20, gtools 3.8.1, and ggplot2 3.0.0. GSEA was performed by selecting the Kyoto Encyclopedia of Genes and Genomes, Gene Ontology and Hallmarks within MSigDB version 6.2. Gene sets with a False Discovery Rate $q$ value $\leq 0.05$ were considered significantly enriched. CMS1-4 profile of CR-CSCs was based on the evaluation of RNA-seq data on matched specimens derived from primary lesions of CRC patients as reported in Linnekamp et al. [51]. Correlation analysis data were obtained using the "R2: Genomics Analysis and Visualization Platform" (http://r2.amc.nl http://r2platform.com) in CRC samples from the Expression Project for Oncology (GEO accession number GSE2109).

\section{Animals and tumor models}

Dissociated CRC sphere cells $\left(5 \times 10^{5}\right)$ were injected subcutaneously into the flank of 5-6-week-old male NOD-SCID mice (Charles River), in a total volume of $100 \mu \mathrm{l}$ of serumfree medium mixed with matrigel (BD) in a ratio of 1:1. The Replacement, Reduction, and Refinement (3Rs) principles were used to estimate the lowest sample size (six mice per group).

Mice were treated for four weeks with PBS (vehicle) or BMP7v (50 $\mu \mathrm{g} / \mathrm{kg}, 3$ days/week) alone or in combination with oxa $(0.25 \mathrm{mg} / \mathrm{kg}$, once a week) and $5-\mathrm{FU}(15 \mathrm{mg} / \mathrm{kg}$, 2 days/week) by i.p. injection, and with taselisib $(5 \mathrm{mg} / \mathrm{kg}$, once daily) by oral gavage. Treatment with BMP4 was performed by intratumoral injection of 100 BMP4-coated beads once a week for 6 weeks. Heparin acrylic beads (Sigma) were incubated with BMP4 $(0.65 \mu \mathrm{g} / \mu \mathrm{l})$ for $1 \mathrm{~h}$ at $37^{\circ} \mathrm{C}$ and washed twice in PBS.

Tumor size was calculated according to the formula: $(\pi /$ 6) $\times(\text { smaller diameter })^{2} \times$ larger diameter.

For in vivo migration experiments, $3 \times 10^{5}$ luciferase (LUC)-transduced CD44v6 ${ }^{+} \mathrm{CR}-\mathrm{CSC}$ s were resuspended in PBS and injected into the spleen of NOD/SCID mice. Following i.p. administration of D-luciferin $(150 \mathrm{mg} / \mathrm{kg}$, Promega), the bioluminescence signal of migrating cells was measured before and $30 \mathrm{~min}$ after the cell injection and immediately after splenectomy up to 12 weeks (every 4 weeks) by using Photon IMAGER instrument (Biospace). No randomization procedure was used. Investigators were not blinded during analysis.

\section{Statistical analysis}

The sample size was chosen to reach a power of $0.9,0.05$ error probability and a large effect size $(>0.5)$ for our groups of treatments. Data were presented as mean \pm standard deviation. Statistical significance was estimated by Analysis of Variance (one way or two ways) with Bonferroni post test, or by unpaired $T$ test. Results were referred to statistically significant as $P<0.05$. * indicates $P<0.05$, ** indicate $P<0.01$, and $* * *$ indicate $P<0.001$.

\section{Study approval}

This study was performed in accordance with the ethical standards of the Institutional Committee on Human Experimentation (authorization CE9/2015, Policlinico Paolo Giaccone, Palermo). All animal experiments were approved by the Institutional Italian Guidelines for Animal Welfare of the University of Palermo (D.L. $n^{\circ} 26$ March 4, 2014, Authorization \#154/2017-PR; Protocol 2B952.5).

Acknowledgements We are thankful to Alessandro Gorgone for technical support, Francesco Calo' for graphics and Tatiana Terranova for editing the manuscript. The research leading to these results has received funding from AIRC under 5x1000 (9979) project-P.I. SG and RDM.

Authors' contributions VV, GS, and RDM conceived and designed the experiments and wrote the manuscript; VV, LRM, AN, SDF, ES, TA, MF, AB, MLC and MT carried out the experiments, analyzed and elaborated data; DSS executed the bioinformatic analysis; GC, FG and CC provided colon cancer specimens; GP and MRB supplied scientific suggestions and critical review; AR provided paraffin-embedded sections of colon adenoma and additional colon cancer specimens; CMT, $\mathrm{XW}, \mathrm{SR}$ and LFS provided the BMP7 variant (BMP7v) and critical comments to the manuscript. All authors revised the manuscript.

Conflict of interest Authors affiliated with Eli Lilly and Company have Eli Lilly and Company shares received via 401 (k) and bonus plans. RDM is an Advisory Board member of HiberCell. RDM and GS are recipients of grants from HiberCell. All other authors declare that they have no conflict of interest.

Publisher's note Springer Nature remains neutral with regard to jurisdictional claims in published maps and institutional affiliations.

Open Access This article is licensed under a Creative Commons Attribution 4.0 International License, which permits use, sharing, adaptation, distribution and reproduction in any medium or format, as long as you give appropriate credit to the original author(s) and the source, provide a link to the Creative Commons license, and indicate if changes were made. The images or other third party material in this article are included in the article's Creative Commons license, unless indicated otherwise in a credit line to the material. If material is not included in the article's Creative Commons license and your intended use is not permitted by statutory regulation or exceeds the permitted use, you will need to obtain permission directly from the copyright holder. To view a copy of this license, visit http://creativecommons. org/licenses/by/4.0/. 


\section{References}

1. Siegel RL, Miller KD, Fedewa SA, Ahnen DJ, Meester RGS, Barzi A, et al. Colorectal cancer statistics, 2017. CA Cancer J Clin. 2017;67:177-93.

2. Zeuner A, Todaro M, Stassi G, De Maria R. Colorectal cancer stem cells: from the crypt to the clinic. Cell Stem Cell. 2014;15:692-705.

3. Batlle E, Clevers H. Cancer stem cells revisited. Nat Med. 2017;23:1124-34.

4. Valent P, Bonnet D, De Maria R, Lapidot T, Copland M, Melo $\mathrm{JV}$, et al. Cancer stem cell definitions and terminology: the devil is in the details. Nat Rev Cancer. 2012;12:767-75.

5. Vitale I, Manic G, De Maria R, Kroemer G, Galluzzi L. DNA damage in stem cells. Mol Cell. 2017;66:306-19.

6. Marcucci F, Stassi G, De Maria R. Epithelial-mesenchymal transition: a new target in anticancer drug discovery. Nat Rev Drug Discov. 2016;15:311-25.

7. Ricci-Vitiani L, Lombardi DG, Pilozzi E, Biffoni M, Todaro M, Peschle $\mathrm{C}$, et al. Identification and expansion of human coloncancer-initiating cells. Nature. 2007;445:111-5.

8. Todaro M, Gaggianesi M, Catalano V, Benfante A, Iovino F, Biffoni $\mathrm{M}$, et al. CD44v6 is a marker of constitutive and reprogrammed cancer stem cells driving colon cancer metastasis. Cell Stem Cell. 2014;14:342-56.

9. Arends JW. Molecular interactions in the Vogelstein model of colorectal carcinoma. J Pathol. 2000;190:412-6.

10. Medema JP, Vermeulen L. Microenvironmental regulation of stem cells in intestinal homeostasis and cancer. Nature. 2011;474:318-26.

11. Clevers H. The intestinal crypt, a prototype stem cell compartment. Cell. 2013;154:274-84.

12. Vermeulen L, Snippert HJ. Stem cell dynamics in homeostasis and cancer of the intestine. Nat Rev Cancer. 2014;14:468-80.

13. Chen D, Ji X, Harris MA, Feng JQ, Karsenty G, Celeste AJ, et al. Differential roles for bone morphogenetic protein (BMP) receptor type IB and IA in differentiation and specification of mesenchymal precursor cells to osteoblast and adipocyte lineages. J cell Biol. 1998;142:295-305.

14. Derynck R, Zhang YE. Smad-dependent and Smad-independent pathways in TGF-beta family signalling. Nature. 2003;425:577-84.

15. Miyazono K, Kamiya Y, Morikawa M. Bone morphogenetic protein receptors and signal transduction. $\mathrm{J}$ Biochem. 2010;147:35-51.

16. Rider CC, Mulloy B. Bone morphogenetic protein and growth differentiation factor cytokine families and their protein antagonists. Biochemical J. 2010;429:1-12.

17. Kosinski C, Li VS, Chan AS, Zhang J, Ho C, Tsui WY, et al. Gene expression patterns of human colon tops and basal crypts and BMP antagonists as intestinal stem cell niche factors. Proc Natl Acad Sci USA. 2007;104:15418-23.

18. Brosens LA, Langeveld D, van Hattem WA, Giardiello FM, Offerhaus GJ. Juvenile polyposis syndrome. World J Gastroenterol. 2011;17:4839-44.

19. Haramis AP, Begthel H, van den Born M, van Es J, Jonkheer S, Offerhaus GJ, et al. De novo crypt formation and juvenile polyposis on BMP inhibition in mouse intestine. Science. 2004;303:1684-6.

20. Massague J. TGFbeta in cancer. Cell. 2008;134:215-30.

21. Thiagalingam S, Lengauer C, Leach FS, Schutte M, Hahn SA, Overhauser J, et al. Evaluation of candidate tumour suppressor genes on chromosome 18 in colorectal cancers. Nat Genet. 1996;13:343-6.
22. Kodach LL, Wiercinska E, de Miranda NF, Bleuming SA, Musler AR, Peppelenbosch MP, et al. The bone morphogenetic protein pathway is inactivated in the majority of sporadic colorectal cancers. Gastroenterology. 2008;134:1332-41.

23. He XC, Zhang J, Tong WG, Tawfik O, Ross J, Scoville DH, et al. BMP signaling inhibits intestinal stem cell self-renewal through suppression of Wnt-beta-catenin signaling. Nat Genet. 2004;36:1117-21.

24. Lombardo Y, Scopelliti A, Cammareri P, Todaro M, Iovino F, Ricci-Vitiani L, et al. Bone morphogenetic protein 4 induces differentiation of colorectal cancer stem cells and increases their response to chemotherapy in mice. Gastroenterology. 2011;140:297-309.

25. Irshad S, Bansal M, Guarnieri P, Davis H, Al Haj Zen A, Baran B, et al. Bone morphogenetic protein and Notch signalling crosstalk in poor-prognosis, mesenchymal-subtype colorectal cancer. J Pathol. 2017;242:178-92.

26. Buijs JT, Henriquez NV, van Overveld PG, van der Horst G, Que I, Schwaninger R, et al. Bone morphogenetic protein 7 in the development and treatment of bone metastases from breast cancer. Cancer Res. 2007;67:8742-51.

27. Kobayashi A, Okuda H, Xing F, Pandey PR, Watabe M, Hirota S, et al. Bone morphogenetic protein 7 in dormancy and metastasis of prostate cancer stem-like cells in bone. J Exp Med. 2011;208:2641-55.

28. Beck SE, Jung BH, Fiorino A, Gomez J, Rosario ED, Cabrera BL, et al. Bone morphogenetic protein signaling and growth suppression in colon cancer. Am J Physiol Gastrointest Liver Physiol. 2006;291:G135-45.

29. Swencki-Underwood B, Mills JK, Vennarini J, Boakye K, Luo J, Pomerantz S, et al. Expression and characterization of a human BMP-7 variant with improved biochemical properties. Protein Expr Purif. 2008;57:312-9.

30. Tate CM, Pallini R, Ricci-Vitiani L, Dowless M, Shiyanova T, D'Alessandris GQ, et al. A BMP7 variant inhibits the tumorigenic potential of glioblastoma stem-like cells. Cell Death Differ. 2012;19:1644-54

31. Tate CM, Mc Entire J, Pallini R, Vakana E, Wyss L, Blosser W, et al. A BMP7 variant inhibits tumor angiogenesis in vitro and in vivo through direct modulation of endothelial cell biology. PLoS One. 2015;10:e0125697.

32. Todaro M, Alea MP, Di Stefano AB, Cammareri P, Vermeulen L, Iovino $\mathrm{F}$, et al. Colon cancer stem cells dictate tumor growth and resist cell death by production of interleukin-4. Cell Stem Cell. 2007;1:389-402.

33. Hemminki A, Mecklin JP, Jarvinen H, Aaltonen LA, Joensuu H. Microsatellite instability is a favorable prognostic indicator in patients with colorectal cancer receiving chemotherapy. Gastroenterology. 2000;119:921-8.

34. Ribic CM, Sargent DJ, Moore MJ, Thibodeau SN, French AJ, Goldberg RM, et al. Tumor microsatellite-instability status as a predictor of benefit from fluorouracil-based adjuvant chemotherapy for colon cancer. New Engl J Med. 2003;349:247-57.

35. Jover R, Castells A, Llor X, Andreu M. Predictive value of microsatellite instability for benefit from adjuvant fluorouracil chemotherapy in colorectal cancer. Gut. 2006;55:1819-20.

36. Guinney J, Dienstmann R, Wang X, de Reynies A, Schlicker A, Soneson $\mathrm{C}$, et al. The consensus molecular subtypes of colorectal cancer. Nat Med. 2015;21:1350-6.

37. Song N, Pogue-Geile KL, Gavin PG, Yothers G, Kim SR, Johnson NL, et al. Clinical outcome from oxaliplatin treatment in stage II/III colon cancer according to intrinsic subtypes: secondary analysis of NSABP C-07/NRG oncology randomized clinical trial. JAMA Oncol. 2016;2:1162-9. 
38. Tenbaum SP, Ordonez-Moran P, Puig I, Chicote I, Arques O, Landolfi $\mathrm{S}$, et al. beta-catenin confers resistance to PI3K and AKT inhibitors and subverts FOXO3a to promote metastasis in colon cancer. Nat Med. 2012;18:892-901.

39. Sneddon JB, Zhen HH, Montgomery K, van de Rijn M, Tward $\mathrm{AD}$, West $\mathrm{R}$, et al. Bone morphogenetic protein antagonist gremlin 1 is widely expressed by cancer-associated stromal cells and can promote tumor cell proliferation. Proc Natl Acad Sci USA. 2006;103:14842-7.

40. Laurila R, Parkkila S, Isola J, Kallioniemi A, Alarmo EL. The expression patterns of gremlin 1 and noggin in normal adult and tumor tissues. Int J Clin Exp Pathol. 2013;6:1400-8.

41. Caja L, Tzavlaki K, Dadras MS, Tan EJ, Hatem G, Maturi NP. et al. Snail regulates BMP and TGF $\beta$ pathways to control the differentiation status of glioma-initiating cells. Oncogene. 2018;37:2515-31.

42. Qi Z, Li Y, Zhao B, Xu C, Liu Y, Li H, et al. BMP restricts stemness of intestinal Lgr5(+) stem cells by directly suppressing their signature genes. Nat Commun. 2017;8:13824.

43. Mani SA, Guo W, Liao MJ, Eaton EN, Ayyanan A, Zhou AY, et al. The epithelial-mesenchymal transition generates cells with properties of stem cells. Cell. 2008;133:704-15.

44. Zeng YH, Zhou LY, Chen QZ, Li Y, Shao Y, Ren WY, et al. Resveratrol inactivates PI3K/Akt signaling through upregulating
BMP7 in human colon cancer cells. Oncol Rep. 2017;38:456-64.

45. Gupta PB, Onder TT, Jiang G, Tao K, Kuperwasser C, Weinberg RA, et al. Identification of selective inhibitors of cancer stem cells by high-throughput screening. Cell. 2009;138:645-59.

46. Castaigne S, Chomienne C, Daniel MT, Ballerini P, Berger R, Fenaux $\mathrm{P}$, et al. All-trans retinoic acid as a differentiation therapy for acute promyelocytic leukemia. I. Clinical results. Blood. 1990;76:1704-9.

47. Fruman DA, Chiu H, Hopkins BD, Bagrodia S, Cantley LC, Abraham RT. The PI3K pathway in human disease. Cell. 2017;170:605-35.

48. Liu P, Cheng H, Roberts TM, Zhao JJ. Targeting the phosphoinositide 3-kinase pathway in cancer. Nat Rev Drug Discov. 2009;8:627-44.

49. Rodon J, Dienstmann R, Serra V, Tabernero J. Development of PI3K inhibitors: lessons learned from early clinical trials. Nat Rev Clinical Oncol. 2013;10:143-53.

50. Ianevski A, He L, Aittokallio T, Tang J. SynergyFinder: a web application for analyzing drug combination dose-response matrix data. Bioinformatics. 2017;33:2413-5.

51. Linnekamp JF, Hooff SRV, Prasetyanti PR, Kandimalla R, Buikhuisen JY, Fessler E, et al. Consensus molecular subtypes of colorectal cancer are recapitulated in in vitro and in vivo models. Cell Death Differ. 2018;25:616-33. 